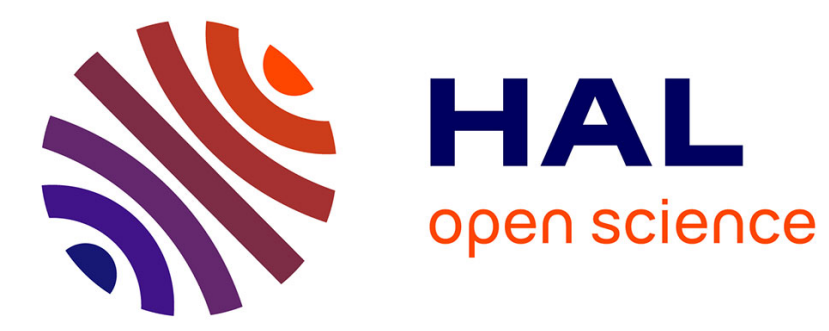

\title{
Do capital market and trade liberalization trigger labor market deregulation?
}

Hervé Boulhol

\section{To cite this version:}

Hervé Boulhol. Do capital market and trade liberalization trigger labor market deregulation?. 2006. halshs-00118951

\author{
HAL Id: halshs-00118951 \\ https://shs.hal.science/halshs-00118951
}

Submitted on 7 Dec 2006

HAL is a multi-disciplinary open access archive for the deposit and dissemination of scientific research documents, whether they are published or not. The documents may come from teaching and research institutions in France or abroad, or from public or private research centers.
L'archive ouverte pluridisciplinaire HAL, est destinée au dépôt et à la diffusion de documents scientifiques de niveau recherche, publiés ou non, émanant des établissements d'enseignement et de recherche français ou étrangers, des laboratoires publics ou privés. 


\section{Centre d'Economie de la Sorbonne}

UMR 8174

U

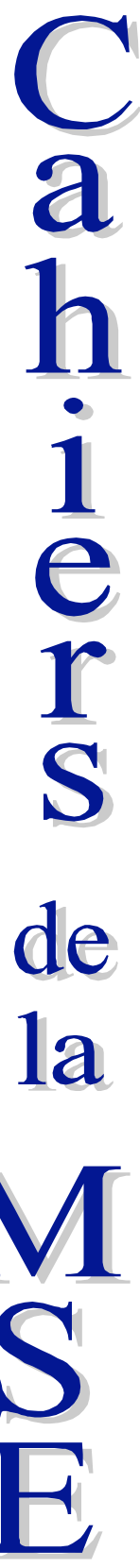

Do capital market and trade liberalization

Trigger labor market deregulation?

Hervé BOULHOL

2006.62

CENTRE NATIONAL

DE LARECHERCHE

SCIENTFIQUE 


\section{DO CAPITAL MARKET AND TRADE LIBERALIZATION TRIGGER LABOR MARKET DEREGULATION?*}

\section{Hervé Boulhol}

IXIS CIB and Centre d'économie de la Sorbonne (University Paris I Panthéon-Sorbonne and CNRS) hboulhol@ixis-cib.com

September 2006

* I am grateful to Pierre Cahuc, Matthieu Crozet, Lionel Fontagné, David Galvin, Philippe Martin, Glenn Rayp and two anonymous referees for their very helpful comments. 


\title{
Résumé
}

Des études précédentes ont montré que la déréglementation sur le marché des produits précède souvent les réformes sur le marché du travail (MT). Ce papier introduit les imperfections du marché du travail dans un cadre d'économie géographique, le niveau optimal de réglementation du MT dépendant des préférences sociales de chaque pays. En raison de la mobilité du capital, l'ouverture de l'économie avec un pays qui a un MT déréglementé met sous pression les institutions du MT. Avec la baisse des coûts liés au commerce qui accroît l'intensité des forces d'agglomération, la réglementation du MT perd en efficacité. La menace de délocalisations entraîne les changements de la politique du MT, ce qui suggère que l'effet de la libéralisation se trouve peut-être surtout dans l'affaiblissement de la protection de l'emploi, avec peu de délocalisations effectives.

Mots clés: Déréglementation, Négociations salariales, Mobilité du capital, Agglomération, Délocalisations

\begin{abstract}
Previous analyses showed that product market deregulation often precedes labor market (LM) reforms. This paper introduces $L M$ imperfections within an economic geography framework, the level of optimal LM regulation being based on each country's social preferences. Due to capital mobility, opening the economy to a country with a deregulated LM puts pressure on LM institutions. As the fall in trade costs increases the intensity of the agglomeration force, LM regulation loses in efficiency. The threat of relocation drives changes in LM policy, which suggests that the effect of liberalization might be found primarily in the weakening of employment protection, resulting in minimal actual relocations.
\end{abstract}

Keywords: Deregulation, Wage Bargaining, Capital Mobility, Agglomeration, Relocations

JEL Classification: F12, F16, F20, J41, J42 


\section{Introduction}

To date, the question of product-labor market interactions has mostly been viewed through the impact of competition on employment and wages. Blanchard (2005) summarizes that the empirical evidence about the role of institutions is mixed and sees the exploration of other interactions as a promising avenue for research. Recently, fom an empirical investigation which addresses multi-collinearity issues that might be responsible for the lack of robustness in previous results, Nicoletti and Scarpetta (2005) conclude that employment gains from product market deregulation are likely to be higher in countries that have rigid labor markets.

Concurrently, recent works at the OECD highlight that product market (PM) and labor market (LM) deregulations are correlated across countries and that the former seems to precede the latter. This correlation is illustrated by Figure 1 taken from Brandt, Burniaux and Duval (2005): changes in PM regulation over 1993-1998 are significantly correlated with the intensity of LM reforms recorded over 2000-2004. Said differently, "countries which have undertaken most labour market reforms recently are also those that had most deregulated their product markets beforehand" (Brandt et al., p.8). Moreover, IMF (2004) provides evidence that trade and financial market reforms have generally preceded domestic PM reforms. Even if an all encompassing liberal economic policy might seek to deregulate in both dimensions, which could explain this positive relationship, the sequence of events tells us more. The main purpose of this paper is to shed light on mechanisms which could account for this interaction, from increased competition in the PM to deregulation in the LM.

Empirical literature has well established that foreign competition can have a negative impact on wages by reducing rents in concentrated sectors (e.g. Borjas and Ramey, 1995). However, lower rents does not mean that the rent-sharing scheme between capital and labor has changed. Rodrik (1997) was probably the first to formalize the idea that import competition might weaken workers' bargaining power. The combination of capital mobility and cheaper trade can also weaken the bargaining position of workers through offshoring by limiting the availability of alternative jobs, a possibility which finds some support in Kramarz (2003) in the case of high-school graduates. Although most empirical analyses do point out that actual relocations affect a small number of workers, a recent poll in France indicates that thirty five percent of people surveyed consider that they, or someone closely related to 
them, face high risks of seeing their job delocalized. There is no doubt that high media coverage explains the extent of such fears, but this perception is factual and it is therefore easy to foresee how it could weaken the workers' bargaining position.

Blanchard and Giavazzi (2003), hereafter BG, is the most influential paper dealing with product-labor market interactions. In an elegant setting combining monopolistic competition and wage bargaining, BG study the dynamic impacts of PM and LM deregulations separately. A short sub-section analyzes the regulation interactions per se and the intuition that PM deregulation leads to LM deregulation in their model is the following: because rents are reduced, unions no longer fight as hard. However, this line of thought should apply $b$ shareholders as well. Based on a similar model, Spector (2004) suggests that PM and LM deregulations tend to reinforce each other.

Going one step further, Ebell and Haefke (2006), endogenizing the bargaining regime, develop a theoretical model and show how intensified product market competition induces a shift from collective to individual bargaining. They suggest that the strong decline in coverage and unionization in the US and the UK might have been a direct consequence of PM reforms in the early 'eighties. Their study is the closest to the main focus of the current paper which contributes to formalizing the idea of Gaston and Nelson (2004) that globalization is transformative, i.e. that its effects do not sum up in its direct impacts on wages and employment but extends to transforming the structures of the labor market. On the empirical front, Bertrand (2004) shows that import competition and increased financial pressures alter the employment relationship in the USA from one governed by implicit contracts into one governed by the market. Dreher and Gaston (2005) find that globalization has contributed to deunionization in OECD countries, while Dumont, Rayp and Willemé (2006) and Boulhol, Dobbelaere and Maioli (2006) provide evidence that international trade has weakened workers' bargaining power in Europe.

The model proposed here brings four new contributions. It is a first attempt to introduce LM imperfections within an economic geography framework. Since the early 'nineties, while geography models have been widely used to analyze European integration, the distinct features and heterogeneity of European LM regulations have been discarded in this literature. The current paper is 
a first step to bridge this gap. We do this in the easiest and most tractable geography model, the footloose capital model (FCM) developed by Martin and Rogers (1995) and further analyzed in Baldwin et al. (2003). Secondly, we take into account one aspect of globalization that does not appear in the papers discussed above, capital mobility, and therefore study the interactions between capital mobility, tradability and LM regulation. Thirdly, the level of LM regulation is endogenized, depending on the country's social preferences. Finally, new mechanisms through which opening the economy could put pressure on LM institutions are highlighted.

The intuition of the model is as follows. As detailed in OECD (2004, Chapter 2), employment protection has as a main objective to improve working conditions and the well-being of workers. It is generally believed however that this comes at a cost for employers and generates insiders/outsiders conflicts of interest. Employment protection therefore most likely raises labor costs and unemployment. Modelling LM regulation using a bargaining model inspired from McDonald and Solow (1985) enables us to include these general features. Rent-sharing is mainly about distributing rents and, as a high level of workers' bargaining power favors employed workers over capital owners, the institution in charge of LM regulation, referred to as "social partners" (SP) hereafter, might choose to regulate the LM based on the country's social preferences. This link between social preferences and LM institutions fits in well with Freeman's (2006) analysis, which stresses that the stylized differences between the two systems organizing the economy of the EU and the USA lie in the strength of collective bargaining and social dialogue versus market-driven worker-employer relationship respectively.

As workers capture some share of the rents, capital return is negatively affected. With capital mobility, in addition to the capital flows inherent in the FCM and which depend on the relative factor endowments, opening the economy to a country that has a fully deregulated LM (because of its own preferences) entails capital outflows. As domestic rents are transferred abroad, the positive effect of LM regulation on average real wages is reduced or even reversed, all the more so that trade costs are high and importing the "delocalized" good is costly. When trade costs fall, the agglomeration force and the costs of regulation in terms of geographical attractiveness gain in intensity. When they are low, even the slightest regulation deters firms from producing domestically whatever the differences in 
factor endowments and productivity levels between countries. LM institutions being endogenized, it is the threat of relocations which drives LM deregulation, neutralizing in turn the actual outflows of capital and relocations.

Therefore, capital mobility induces SP to deregulate. Falling trade costs puts additional pressure on LM institutions (at least between countries of similar population and development levels) and, with full trade liberalization, even the most pro-worker SP will optimally choose a fully deregulated LM. In terms of SP utility, opening the economy is found to be, most generally, beneficial. However, unless trade costs reach a low enough level, it has a detrimental effect if SP have a strong pro-worker inclination.

This way of formalizing LM regulation bears some resemblance to the tax competition models. One fundamental difference is that, in contrast to the tax competition literature, there is no pubic good to be financed by the tax receipts, which are the target of the tax competition. Here, the benefits of the regulation simply accrue to workers in the rent / unionized sector. Moreover, the link between regulation and social preferences highlights that the questions at stake are deeply rooted in the history of social relationships and collective choice. Another difference is that this "social competition" can arise between countries identical in terms of size and factor endowments. The remainder of the paper is organized as follows. Section 2 integrates LM imperfections into the FCM and Section 3 focuses on the open economy. Section 4 describes the role of social preferences in optimal LM regulation and shows how capital mobility and trade liberalization induce changes in LM regulation. Finally, Section 5 concludes.

\section{Model}

In this and the following sections, the level of labor market regulation is considered as given, whereas in Section 4, it is treated as endogenous and determined by social preferences.

\subsection{Footloose capital model with labor market regulation}

The setting of the model is the FCM. The two factors are labor and capital, denoted $L$ and $K$. The utility function of each individual is a Cobb-Douglas CES nest of the consumption of two goods:

$$
V=\alpha^{-\alpha} \cdot(1-\alpha)^{-(1-\alpha)} \cdot C_{R}^{\alpha} \cdot C_{A}^{1-\alpha}
$$


One sector produces a homogenous good using only labor under constant returns and perfect competition and is commonly called sector $A$. The rent sector $R$ produces the Dixit-Stiglitz good composed of a mass $n$ of differentiated products under monopolistic competition.

$$
C_{R}=\left[\int_{0}^{n} c(i)^{(\sigma-1) / \sigma} \cdot d i\right]^{\sigma /(\sigma-1)} \quad, \quad \sigma>1
$$

One unit of capital is required to produce one variety $i$ of the differentiated good. For each variety, labor is the only variable input and the unit labor cost is $\beta$ times the wage. In this setting, entry is constrained by the capital endowments and the number of varieties $n$ equals $K$ in autarky. Good $A$ is the numeraire and the unit choice is such that one unit of labor produces one unit of the good:

$$
X_{R}=L_{R} / \beta \quad ; X_{A}=L_{A} \quad ; \quad p_{A}=1
$$

The only difference with the standard FCM lies in the decision by social partners to regulate the LM based on social preferences and the battle of wills. To reflect the idea that regulating the LM is essentially related to rent sharing, the level of employment protection is characterized by the bargaining power of workers, $\gamma$, as in BG. Although within this framework, the benefits of regulation are limited to pecuniary advantages, we mean it to encompass the conditions which make workers happier in their job more generally. For the firm producing the variety $i$, workers and shareholders bargain over wages and employment simultaneously. The Nash bargaining leads to the maximization of the product of the parties' surplus weighted by their bargaining strength, i.e. omitting the subscript $i$ for variety:

$$
[(w-z) \cdot l]^{\gamma}[p(x) \cdot x-w \cdot l]^{1-\gamma}
$$

where $z$ is the reservation wage. First order conditions on wages and employment lead to:

$$
p=\mu . \beta . z \quad ; w=[1+\gamma \cdot(\mu-1)] z \equiv v . z \quad ; \gamma \in[0,1] \Leftrightarrow v \in[1, \mu]
$$

where $\mu=\sigma /(\sigma-1)$. Classically under efficient bargaining with a homothetic utility function, equation (5) states that the marginal revenue of labor is the reservation wage and clarifies that sector- $R$ workers receive a share $\gamma$ of the total rent $(\mu-1)$.

The overall LM operates along the lines of McDonald and Solow (1985). Workers not employed in the rent sector could always occupy a lower paid job in the perfectly competitive sector and therefore, the reservation wage $z$ equals the wage in sector $A$ which is unity. The alternative is to be unemployed, 
total unemployment being denoted $U$. Indeed, being unemployed is supposed to give more time to search for a sector- $R$ job and therefore a better chance to obtain one. This creates a positive relationship between the "sectoral unemployment rate" $u_{R}$ and the potential reward of obtaining a well paid job, i.e. the surplus enjoyed by manufacturing workers, $\gamma \cdot(\mu-1) \equiv v-1$. The reason is that, within this framework, a higher bargaining power raises the expected return from being unemployed relative to the return from working in sector $A$. The equilibrium unemployment rate is obtained when the expected utility of an unemployed person matches that of a sector $A$ employed worker.

$$
u_{R} \equiv U /\left(U+L_{R}\right) \quad, \quad u_{R}=f(v) \quad, \quad f^{\prime}>0 \quad, \quad f(1)=0 \quad, \quad z=w_{A}=1
$$

In order to understand this mechanism through a simple example, consider the Harris-Todaro case where a sector- $A$ worker gives up any opport unity to find a better paid job in the next period, whereas an unemployed person gets a probability $q$, negatively related to the "sectoral unemployment rate" $u_{R}$, to get a sector- $R$ job: $q=q\left(u_{R}\right), q^{\prime}<0$. If $d$ denotes the exogenous unemployment benefits, $h$ the exogenous probability to lose a high-paid job and $r$ the discount rate, the steady state unemployment is given by Bellman's equations which lead to the arbitrage condition: $q \cdot w+(h+r) \cdot d=(q+h+r) \cdot z \Leftrightarrow v-1=\frac{(h+r) \cdot(1-d)}{q\left(u_{R}\right)}$, hence the positive relationship $f$.

As in BG, unemployment arises from the bargaining scheme. Moreover, following McDonald and Solow, the transitional unemployment differs from the standard notion of search unemployment. Indeed, at each moment, the unemployed do not decide between accepting and rejecting offers; they take the first manufacturing job available to them. Because some sectors are perfectly competitive and others not, regulation de facto generates segmented labor markets. Therefore, focusing on the function $f$ is a short cut capturing the essential component of the LM regulation trade-off, at least as it is generally perceived. Indeed as Saint-Paul (2004) summarizes, "a rough consensus emerged that high unemployment in Europe was due to labor market rigidities" which "increase the equilibrium rate of unemployment by boosting the incumbent employee's bargaining power in wage setting". The more regulated the $L M$, i.e. the higher the bargaining power $\gamma$, the better off the rent-sector workers, the 
higher the unemployment rate. ${ }^{1}$ Also, looking at the source of unemployment, i.e. the surplus $\gamma .(\mu-1)$, highlights the complementary role of PM and LM regulation. Despite the focus here not being on domestic PM deregulation, it is clear that within this setting, the more the PM is regulated (high $\mu$, low $\sigma)$, the greater the impact of LM deregulation on the unemployment rate, and vice versa.

\subsection{Autarky}

In addition to the trade-off discussed above, the regulation has a negative impact on the return to capital, $\pi$, because part of the rents are transferred to workers. Indeed, for each sector- $R$ firm:

$$
\pi=p \cdot x-w \cdot l=(\mu-v) \cdot l=(\mu-1) \cdot(1-\gamma) \cdot l \quad \Rightarrow \quad \pi \cdot K=n \pi=(\mu-1) \cdot(1-\gamma) \cdot L_{R}
$$

Total GDP is given by $I=p \cdot X_{R}+X_{A}=\mu \cdot L_{R}+L_{A}$ and maximization of utility leads to:

$$
L_{A}=(1-\alpha) \cdot I \quad \Rightarrow \quad \alpha \cdot L_{A}=\mu \cdot(1-\alpha) \cdot L_{R}
$$

Because the relative price of the goods is not affected by the regulation, relative employment is not either, when capital is immobile. However in the open economy, efficient bargaining does not have a distributive effect only; it also has an allocative impact due to specialization. Denoting the country unemployment rate $u$, equation (8) and LM clearing give the sectoral employment levels:

$$
L_{R}=\frac{\alpha \cdot(\sigma-1)}{\sigma-\alpha} \cdot L \cdot(1-u) \quad, \quad L_{A}=\frac{\sigma \cdot(1-\alpha)}{\sigma-\alpha} \cdot L \cdot(1-u)
$$

The return on capital depends on the capital labor ratio $\kappa \equiv K / L$ and is obtained using equation (7):

$$
\pi=\frac{b}{\kappa \cdot(1-b)} \cdot(1-\gamma) \cdot(1-u)
$$

where $b \equiv \alpha / \sigma$ is positively related to the share of the differentiated good sector in the economy and to the market power; $b$ is a measure of the size of the rents in the economy. Importantly, as it will be the case throughout the paper, the FCM is obtained in the special case of the totally deregulated LM, i.e. with $\gamma=0$ and therefore $u=0$. LM regulation reduces capital return both directly, by transferring part of the rents to workers and indirectly, through the unemployment rate, by reducing the labor endowment available to the economy. Finally, to close the model, we need to derive the unemployment rate:

\footnotetext{
${ }^{1}$ Even though this is the general perception, the empirical support of the link between various measures of the strictness of Employment Protection Legislation and the unemployment rate had so far seriously lacked robustness (see Baker and al., 2005). However, Nicoletti and Scarpetta (2005) bring new evidence in support of this relationship.
} 


$$
u=\frac{U}{L}=\left(1-\frac{L_{A}}{L}\right) u_{R}=\left(1-\frac{L_{A}}{L}\right) \cdot f(v)=\frac{\alpha \cdot(\sigma-1) \cdot f(v)}{\sigma-\alpha-\sigma \cdot(1-\alpha) \cdot f(v)}
$$

This expression highlights that the country unemployment rate is the product of the "sectoral" unemployment rate and of the complement of the employment in sector $A$. This remains true with market opening and therefore, liberalization might wipe out unemployment as a result of specialization in sector $A$, should capital move abroad. However in autarky, the unemployment rate is positively related to the level of LM regulation unambiguously. Obviously, the lower the share of the rent / unionized sector in the economy, $\alpha$, the lower the impact of regulation overall and the lower the country unemployment rate.

\section{Open economy}

There are two countries, an asterisk referring to the foreign country. International trade in good $A$ is costless, whereas trade costs for good $R$ are iceberg. $\tau$ denotes the trade costs for foreign products sold domestically and vice-versa for $\tau^{*}$. Labor is immobile and capital perfectly mobile between countries. Moreover, capital owners are assumed to consume in their home country only. Therefore in the FCM, capital is better thought of as physical capital. The two countries may differ in the factor endowments and productivity, the level of labor productivity in the foreign country being $A^{*}$ times that in the domestic country:

$$
X_{R}^{*}=A^{*} \cdot L_{R}^{*} / \beta \quad ; \quad X_{A}^{*}=A^{*} \cdot L_{A}^{*}
$$

The effect of $A^{*}$ simply amounts to a change in the foreign effective labor endowment which becomes $A^{*} L^{*}$. The general case enables us to consider situations in which trade is driven by differences in productivity, relative endowments, size and trade policy. In addition, the countries can differ in their social preferences; in particular, the foreign country is assumed to have preferences so that its LM is totally deregulated, but sub-section 4.4 considers strategic LM policy. This is reminiscent of Davis (1998) who studies the "America versus Europe dichotomy" in a general equilibrium Heckscher-Ohlin model. While Davis analyzes the impact of minimum wages, we focus on another aspect of LM imperfections and include the advances of the new economic geography. Moreover, this setting can also be thought of in the context of European countries different in terms of size, development level and also LM regulation. 
The movement of capital is fostered by two components. Firstly, in the absence of LM regulation, capital would flow according to the combination of the market access effect (agglomeration force) and the market crowding effect (dispersion force): in the FCM, the demand linkages are absent because income from capital is repatriated and therefore, agglomeration is not self-reinforcing. The resulting sign of these two forces in the standard FCM depends on the relative "size" of the countries, itself a function of the relative factor shares of capital and (effective, in the extension herein) labor, whereas the overall intensity depends on the level of trade costs. Secondly, due to regulation, as shareholders have to forsake part of the rents in the domestic country, the return on capital is lower ceteris paribus than in the foreign country. With capital mobility, this obviously tends to trigger an outflow of capital abroad. At equilibrium, he share of firms located in the domestic country, $s_{n}$, equalizes capital returns by combining these two components.

Two variables are essential for the characterization of the equilibrium: the location of firms represented by the share of firms producing in the domestic country, $s_{n}$, and the unemployment rate, $u$, in the domestic country, and Appendix 1 gives all the details. Equilibrium in good $R$ leads to the expression of the capital return:

$$
\pi=\frac{b}{\kappa^{W} \cdot(1-b)} \frac{(1-\gamma) \cdot\left(1-u \cdot s_{L}\right)}{1-\gamma+\gamma \cdot s_{n}}
$$

where $s_{L}=L /\left(L+A^{*} \cdot L^{*}\right)$ is the domestic effective labor share and $\kappa^{W}=\left(K+K^{*}\right) /\left(L+A^{*} \cdot L^{*}\right)$ the world capital labor ratio. As in autarky, LM regulation in the domestic country reduces the world capital return through the two channels identified before. The impact of unemployment on the return of capital in the global market depends upon the domestic labor share, hence the $u . s_{L}$ term. As shown below, when the activity is fully agglomerated in the foreign country, equation (13) remains valid. In this situation, the source of unemployment, i.e. the presence of a rent sector, disappears from the home country and the capital return is equal to $1 / \kappa^{W} \cdot b /(1-b)$ which is the FCM return.

We assume that the non-full-specialization condition (see Baldwin et al.), that is the condition which ensures that good $A$ is produced in both countries, is respected. Here, this condition is $b<\left(1-s_{L}\right) /\left(\sigma-s_{L}\right)$. Denoting the free-ness of trade, i.e. the so-called phi-ness, $\phi \equiv \tau^{1-\sigma}$ and taking 
equilibrium in sector $A$ (or alternatively the balanced current account condition) into account lead to the first relationship between the share of firms and the unemployment rate in the home country:

$$
s_{n}(\gamma, \phi)=\frac{s \cdot\left(1-\phi \cdot \phi^{*}\right)-\phi \cdot\left(1-\phi^{*}\right)-\gamma \cdot\left[\phi \cdot \phi^{*}+s \cdot\left(1-\phi \cdot \phi^{*}\right)\right]-u \cdot s_{L}\left[(1-\phi-\gamma)-b \cdot s_{K}^{*} \cdot\left(1-\phi \cdot \phi^{*}\right) \cdot(1-\gamma)\right]}{(1-\phi) \cdot\left(1-\phi^{*}\right)-\gamma .\left[s .\left(1-\phi . \phi^{*}\right)-\phi^{*} .(1-\phi)+b \cdot s_{K}^{*} \cdot\left(1-\phi . \phi^{*}\right)\right]-u \cdot s_{L}(1-\phi-\gamma) \cdot\left(1-\phi^{*}\right)}
$$

where $s \equiv b \cdot s_{K}+(1-b) \cdot s_{L}$, a weighting average of the factor shares, represents the relative "size" of the domestic country: in the standard FCM, $s$ is the share of domestic GNP. Finally, LM equilibrium in the domestic country gives the second relationship:

$$
\frac{u}{1 / s_{L}-u}=\frac{b}{1-b} \cdot(\sigma-1) \cdot \frac{f(v)}{1-f(v)} \cdot \frac{s_{n}}{1-\gamma+\gamma \cdot s_{n}}=\frac{u^{\text {autarky }}(\gamma)}{1-u^{\text {autarky }}(\gamma)} \cdot \frac{s_{n}}{1-\gamma+\gamma \cdot s_{n}}
$$

Equation (15) is easily interpreted. In the open economy, unemployment is driven by two channels. The first is the "sectoral unemployment" which directly leads to the autarky unemployment rate and to the first term on the RHS. The second channel is the number of sector- $R$ firms producing domestically, which leads to the second term. Therefore, full employment is reached either because the LM is deregulated $(\gamma=0 \Leftrightarrow v=1)$ which eliminates the primary cause or because the $R$ economy is aggregated in the foreign country $\left(s_{n}=0\right)$. We can therefore expect the open economy unemployment rate to be hump shaped, as a function of the workers' bargaining power. This is a result of the conflicting effects of the increase in the "sectoral" unemployment rate and of capital outflow, which triggers the decrease in the share of sector $R$ in domestic production. The outcome, that unemployment tends to disappear when relocations expand, could at first seem strange. However, this follows very logically from two assumptions. First, the adjustment of labor in the path towards the open economy is neglected, as the equilibrium described here corresponds to the long run equilibrium. Second, it is a direct consequence of the LM model based on the trade-off between regulation and unemployment. Concretely, it implies that the unemployment which disappears with the shrinking of the rent / unionized sector is the part of total unemployment resulting specifically from the insider / outsider conflict. Given the levels of the trade costs and bargaining power, equations (14) and (15) define the location of firms and the equilibrium unemployment rate, leading to Proposition $1 \mathrm{~A}$.

\section{Proposition 1A. Location of firms and unemployment rate in the open economy}

(i) Unilateral trade costs. Given the level of the bargaining power and of the foreign trade cost, if domestic trade costs are low enough, then all Rfirms are agglomerated in the 
foreign country. Formally, the unilateral $(U)$ "sustain point" $(S)$ for the agglomeration in the foreign $(F)$ country, $\phi_{S}^{U, F}$, is given by:

$\phi_{S}^{U, F} \equiv \frac{s .(1-\gamma)}{1-\phi^{*} .(1-s) .(1-\gamma)}<1 \quad \Leftrightarrow \quad \gamma=g\left(\phi_{S}^{U, F}, \phi^{*}\right) \equiv 1-\frac{\phi_{S}^{U, F}}{\phi_{S}^{U, F} . \phi^{*}+s .\left(1-\phi_{S}^{U, F} \cdot \phi^{*}\right)}$

$\phi \geq \phi_{S}^{U, F} \Rightarrow s_{n}=0 \quad ; \quad \partial \phi_{S}^{U, F} / \partial s \geq 0 \quad, \quad \partial \phi_{S}^{U, F} / \partial \phi^{*} \geq 0 \quad, \quad \partial \phi_{S}^{U, F} / \partial \gamma \leq 0$

The share of firms located in the domestic country is a decreasing function of both the workers' bargaining power and the domestic phi-ness of trade and an increasing function of the foreign phi-ness: $\quad \frac{\partial s_{n}}{\partial \gamma} \leq 0 \quad, \quad \frac{\partial s_{n}}{\partial \phi} \leq 0 \quad, \quad \frac{\partial s_{n}}{\partial \phi^{*}} \geq 0$

(ii) Bilateral trade costs: $\phi=\phi^{*}$. Given the level of the bargaining power, if trade costs are low enough, then all R-firms are agglomerated in the foreign country. Formally, the bilateral (B) "sustain point" (S) for the agglomeration in the foreign (F) country, $\phi_{S}^{B, F}$ is such that:

$$
\begin{aligned}
& \gamma=\tilde{g}\left(\phi_{S}^{B, F}\right) \equiv g\left(\phi_{S}^{B, F}, \phi_{S}^{B, F}\right)=1-\frac{\phi_{S}^{B, F}}{\phi_{S}^{B, F^{2}}+s .\left(1-\phi_{S}^{B, F^{2}}\right)} \Leftrightarrow \phi_{S}^{B, F}=\tilde{g}^{-1}(\gamma)<1 \quad, \tilde{g}^{\prime}<0 \\
& \phi \geq \phi_{S}^{B, F} \Rightarrow s_{n}=0 \quad ; \quad \partial \phi_{S}^{B, F} / \partial s \geq 0 \quad, \quad \partial \phi_{S}^{B, F} / \partial \gamma \leq 0
\end{aligned}
$$

The share of firms located in the domestic country is a decreasing function of the workers' bargaining power: $\frac{\partial s_{n}}{\partial \gamma} \leq 0$

(iii) Unemployment. The domestic unemployment rate is hump-shaped in $\gamma$. At the foreign agglomerated equilibrium, the domestic country is, by definition, fully specialized in good $A$ and the unemployment rate is zero: $\phi \geq \phi_{S}^{F} \Rightarrow u=0$

The proof follows directly from equations (14) and (15) and is given in Appendix 1. From (15) we infer that, at the level of trade costs where the firms are agglomerated in the foreign country, the unemployment rate is zero. Based on the numerator of (14), it follows necessarily that this level is defined by $\gamma=g\left(\phi, \phi^{*}\right)$ which characterizes the sustain point. Naturally, his sustain point is an increasing function of the size of the domestic country: the larger the domestic country the lower the domestic trade costs necessary to make the agglomeration in the foreign country sustainable. It is interesting to consider the case where the relative capital share $s_{K}$ is equal to the relative effective 
labor share $s_{L}$ and therefore to the "size" $s$. This situation is very natural since the steady state in a typical growth model is such that capital is proportional to effective labor. Between countries of comparable population levels, ignoring the effect of LM regulation, relocations tend to take place from the poor to the rich country. This is because the differences in labor costs reflect the differences in productivity and therefore, the level of development becomes the main determinant of the size of the market and of the location of firms. Of course, in the general case where countries have different population levels the two components of effective labor, productivity $(A)$ and population $(L)$, matter.

The fact that the share of domestic firms is an increasing function of $\phi^{*}$ is due to the better attractiveness of being located in the domestic country when it is cheap to serve the foreign market. The opposite applies for the relation with $\phi$. In the bilateral case $\left(\phi=\phi^{*}\right)$, these two effects oppose each other and the relative size of the countries becomes crucial.

$$
\begin{aligned}
\phi \leq \phi_{S}^{B, F} \quad \Leftrightarrow \quad \gamma \leq \psi \Rightarrow s_{n} \approx \frac{\psi-\gamma}{\chi-\gamma . \psi} \approx \frac{\psi-\gamma}{\chi} \\
\text { with } \left.\psi \equiv \tilde{g}(\phi) \in[0,1], \tilde{g}^{\prime}<0 \quad \text { and } \chi \equiv \frac{(1-\phi)^{2}}{\phi^{2}+s \cdot\left(1-\phi^{2}\right)} \quad \text { (if } s=1 / 2 \text { then } \chi=2 \psi\right)
\end{aligned}
$$

From equation (16), it is straightforward to derive the scissors diagram (Figure 2), which illustrates how the location of firms depends on the size, $s$, when $\phi$ and $\gamma$ are given.

$$
s_{n}=\frac{\psi-\gamma}{\chi} \Leftrightarrow s_{n}=\frac{1}{2}+\frac{1+\phi}{1-\phi} \cdot\left(s-\frac{1}{2}\right)-\gamma \cdot \frac{\phi^{2}+s \cdot\left(1-\phi^{2}\right)}{(1-\phi)^{2}}
$$

Compared to the FCM, there is an extra term, the last one on the RHS, which depends on the level of LM regulation. This term shifts the diagram to the right. As in the FCM, the larger country tends to appropriate more capital and the home market effect increases with the phi-ness of trade. Importantly, the additional negative effect due to regulation dominates when trade costs are low:

$$
\frac{\partial s_{n}}{\partial \phi}=\frac{2}{(1-\phi)^{2}} \cdot\left(s-\frac{1}{2}\right)-\frac{2 \cdot \gamma}{(1-\phi)^{3}} \cdot[\phi+s \cdot(1-\phi)]
$$

Indeed, an inspection of the power in the denominators makes it clear that when trade costs are low, the LM regulation effect dominates whatever the size of the domestic country that respects the non-full specialization condition. This is because when the goods market becomes more integrated, the 
location of firms is less relevant and therefore, only the negative impact of regulation on capital return matters for firm's location decision: $\lim _{\phi \rightarrow 1} \tilde{g}(\phi)=0 \Rightarrow \forall \gamma \neq 0, \lim _{\phi \rightarrow 1} s_{n}=0$.

Appendix 1 shows that the unemployment rate is given by:

$$
\phi \leq \phi_{S}^{B, F} \Leftrightarrow \gamma \leq \psi \Rightarrow u \approx \frac{(\psi-\gamma)}{\chi \cdot(1-\gamma)} \cdot \frac{u^{\text {autarky }}(\gamma)}{s_{L}}
$$

The unemployment rate is exactly zero when the LM is fully deregulated or when the phi-ness of trade exceeds the sustain point. Based on equation (15), the sensitivity of the unemployment rate to trade costs has the same sign as that of the share of domestic firms. Figure 3a illustrates this pattern for different levels of trade costs in the symmetric country case $\left(s_{K}=s_{L}=s=1 / 2\right)$. When trade costs fall, as more firms locate abroad (equation 17 with $s=1 / 2$ ), the domestic country specializes in good $A$, and the unemployment rate decreases. Figures $3 \mathrm{~b}$ and $3 \mathrm{c}$ illustrate how the domestic share of firms and the world capital return react to the workers' bargaining power for various levels of trade costs. The difference in capital returns between the two countries drives the location of firms and the equilibrium location is the one which equalizes these returns. When this is not possible (domestic bargaining power too high, i.e. $\gamma \geq \psi$ ), the agglomeration in the foreign country is the only equilibrium. Moreover, in autarky the greater the bargaining power, the lower the domestic return on capital. It therefore requires more firms to move to make the returns converge. In addition, as trade costs fall it is easier to serve the domestic market from abroad, which renders the location in the foreign country even more appealing. As it is clear from Figure $3 c$, with market opening, nominal capital return, i.e. capital return relative to sector- $A$ wages, increases in the domestic country. Thus, at constant bargaining power, as inter-sector relative wages are constant, market opening benefits capital owners relative to wage earners in the regulating country.

Up to now, the model has been analyzed by assuming a given bargaining power and assessing the impact of varying trade costs. However, it is clear that all the results can be interpreted by holding the phi-ness of trade constant and studying the impact of varying the regulation level. In particular, this enables an easier characterization of the agglomerated equilibrium in the domestic country, which has been left aside. In this spirit and as a transition to the following section, Proposition $1 \mathrm{~A}$ can be interpreted from the point of view of the "social partners" who choose the level of LM regulation. 


\section{Proposition 1B. Minimum and maximum levels of labor market regulation}

(i) Agglomeration in the foreign country. Given the level of trade costs, there exists a maximum level of the workers' bargaining power beyond which all firms move abroad:

$\exists \gamma_{\max }=\psi=\max \left[g\left(\phi, \phi^{*}\right), 0\right]=\max \left[1-\frac{\phi}{\phi . \phi^{*}+s .\left(1-\phi . \phi^{*}\right)}, 0\right] \leq 1$ such that $\gamma \geq \gamma_{\max } \Rightarrow s_{n}=0$

This maximum level of the bargaining power is a decreasing (increasing) function of the domestic (foreign) phi-ness. In the bilateral case, it is decreasing with the phi-ness.

$\gamma_{\text {max }}\left(\phi=0, \phi^{*}\right)=1, \quad \gamma_{\text {max }}\left(\phi=1, \phi^{*}\right)=0, \partial \gamma_{\max } / \partial \phi \leq 0, \partial \gamma_{\max } / \partial \phi^{*} \geq 0, d \gamma_{\max }\left(\phi=\phi^{*}\right) / d \phi \leq 0$

(ii) Agglomeration in the domestic country. Given the level of trade costs, if the domestic country is large enough, there exists a minimum level of the workers' bargaining power under which all firms operate in the domestic country.

$$
s \geq \frac{1-\phi^{*}}{1-\phi \cdot \phi^{*}} \Rightarrow \exists \gamma_{\min } \approx \frac{1-\phi \cdot \phi^{*}}{\phi^{*}}\left(s-\frac{1-\phi^{*}}{1-\phi \cdot \phi^{*}}\right) \geq 0 \text { such that } \gamma \leq \gamma_{\min } \Rightarrow s_{n}=1
$$

This minimum level of the bargaining power is a decreasing (increasing) function of the domestic (foreign) phi-ness. In the bilateral case, it is hump shaped in the phi-ness.

$$
\begin{aligned}
& \gamma_{\text {min }}\left(\phi=1, \phi^{*}\right)=0, \quad \gamma_{\text {min }}\left(\phi, \phi^{*}=0\right)=0, \partial \gamma_{\text {min }} / \partial \phi \leq 0, \partial \gamma_{\text {min }} / \partial \phi^{*} \geq 0 \\
& \text { If } s<1 / 2 \text { then } \phi=\phi^{*} \Rightarrow \gamma_{\min }=0 \\
& \text { a) } \phi<(1-s) / s \Rightarrow \gamma_{\text {min }}=0 \\
& \text { If } \left.s>1 / 2 \text { then } \phi=\phi^{*} \Rightarrow b\right)(1-s) / s<\phi<((1-s) / s)^{1 / 2} \Rightarrow d \gamma_{\min } / d \phi \geq 0 \\
& \text { c) }((1-s) / s)^{1 / 2}<\phi \Rightarrow d \gamma_{\min } / d \phi \leq 0
\end{aligned}
$$

Figure 4 illustrates the preceding results. For each chart, Proposition $1 \mathrm{~A}$ can be read horizontally for a given bargaining power, whereas Proposition 1B is read vertically for a given level of trade cost. The bilateral case is explained as follows. When trade costs are prohibitive no agglomeration is possible. When the goods market is fully integrated, the least level of regulation triggers the agglomeration in the foreign country. At intermediate levels, the agglomeration rents are the strongest (see Baldwin et al., Chapter 15) and, if large enough, the domestic country can attract capital and support some level of regulation. The hump-shape of $\gamma_{\min }$ when the domestic country is large enough is related to the well-identified hump-shape of the agglomeration rents in the tax competition models. However, no 
matter how large, if the regulation level exceeds a certain threshold, then all firms go abroad. We are now in a position to study the impact of market liberalization on LM regulation.

\section{Endogenous labor market regulation}

\subsection{Autarky}

In our model, the regulation of the LM clearly has a negative impact on real GDP. Indeed, the price index in autarky, $G=p^{\alpha} / K^{\alpha /(\sigma-1)}=\left(\mu . \beta . K^{1 /(1-\sigma)}\right)^{\alpha}$, does not change with the level of regulation and given equation (9), real GDP is:

$$
(I / G)^{\text {autarky }}=\left(\mu \cdot \beta \cdot K^{1 /(1-\sigma)}\right)^{-\alpha} \cdot\left(\mu \cdot L_{R}+L_{A}\right)=\frac{K^{\alpha /(\sigma-1)}}{\mu^{\alpha} \cdot \beta^{\alpha}} \cdot \frac{L \cdot(1-u)}{1-b}
$$

The higher the unemployment rate, the lower the GDP. Consequently, a utilitarian government would choose to totally deregulate the LM. However, we consider the case where the social partners (SP) have an objective different from the maximization of the GDP depending on the extent of their prolabor (vs pro-capital) orientation, represented by parameter $\lambda$. Specifically, it is assumed that they may put less weight on capital income, the greater the parameter $\lambda$.

$$
O B J_{\lambda}=\frac{w_{A} \cdot L_{A}+w_{R} \cdot L_{R}+(1-\lambda) \pi \cdot K}{G} \quad, \lambda \in[0,1]
$$

When $\lambda=0$, SP are indifferent to the distribution of revenue and the objective function boils down to the real GDP. In the other extreme when $\lambda=1$, SP only cares about labor income. As argued by Saint-Paul, LM regulation is mainly about distributing rents and we focus here on this distinct aspect of regulation. Furthermore, Saint-Paul demonstrates that this type of regulation is inefficient in the sense that a government with the same objective would primarily choose to redistribute through taxation and hence avoid the detrimental effect of unemployment. However, there are different reasons why it is interesting to analyze the consequences of LM regulation. Firstly, SP are mostly thought of as a mixed representation of union and employer organizations. Tax instruments are beyond their reach. Secondly, Saint-Paul shows how such a regulation might emerge as a result of the strength of various lobbies or even of the coalition between insiders and capital owners to the expense of outsiders. Thirdly, we intend to keep away from issues related to capital taxation per se. 
Although the orientation of the SP, $\lambda$, or social preferences could come from a political process, we consider that it is idiosyncratic to a particular country and determined by such deep causes as the history of social relations, the battle of wills between various lobbies, the political orientation or the structure of shareholding - for instance, a country where the culture of stockholding is deeply rooted or where pension funds play an important role is likely to have a low $\lambda$. For all these reasons, trying to model the social preferences parameter explicitly based on such country's characteristics as factor endowments is likely to prove both overly ambitious and unsatisfactory: countries may differ in their social preferences which shape different institutions. What explains the differences in so-called social models, between the USA and continental Europe, between the various LM institutions in the E.U.?

Appendix 2 shows that in autarky:

$$
O B J_{\lambda}=c t e .(1-u) \cdot[1-\lambda \cdot b \cdot(1-\gamma)]
$$

Equation (22) makes it clear that regulation has two effects on SP utility: a negative one through unemployment which reduces GDP and a positive redistributive effect, the term between brackets. This term is all the greater for a given bargaining power, when the size of the rents is higher $(b)$ and when the SP are the more pro-labor $(\lambda)$. Differentiating (22) leads to:

$$
\frac{d O B J_{\lambda}}{d \gamma} \geq 0 \quad \Leftrightarrow \quad \gamma \leq 1-\frac{1}{b . \lambda}+\frac{1-u}{d u / d \gamma}
$$

When the expression on the RHS is positive, SP utility increases until the bargaining power hits the value of the RHS term, from which it then decreases: this value is therefore the optimal regulation level from the point of view of SP. Two points are worth noting. When the pro-labor orientation $\lambda$ is small enough, the RHS of the inequality is negative and the SP opt for deregulation. Secondly, the higher the sensitivity of the unemployment rate to the regulation, $d u / d \gamma$, the lower the RHS, and therefore the lower the optimal level of the bargaining power.

In order to move further, we have to specify a functional form $f$ respecting (6) and to remain as general as possible, we choose $f$ depending on a parameter $\delta$ which measures how sensitive the unemployment rate is to the regulation level. Appendix 2 gives the full derivation, the exact function being chosen to facilitate the calculations:

$$
u_{R}=f(\gamma) \approx \delta .(v-1)=\delta /(\sigma-1) \cdot \gamma
$$


This function fits the Harris-Todaro case sketched out in sub-section 2.1 almost perfectly with $\delta=\frac{h}{h+r} \cdot \frac{1}{1-d} .^{2}$ As one might expect in that case, $\delta$ is an increasing function of the probability to loose a job, $h$, and of the unemployment benefits, $d$. Given this functional form, the autarky unemployment rate is:

$$
u=1-\exp \left(-\frac{b}{1-b} \cdot \delta \cdot \gamma\right) \approx \frac{b}{1-b} \cdot \delta \cdot \gamma
$$

increasing with $b, \delta$ and $\gamma$ unambiguously. Proposition 2 indicates the optimal regulation level.

\section{Proposition 2. Optimal labor market regulation in autarky}

The optimal level of regulation $\hat{\gamma}(\lambda)$ is an increasing function of the social preferences parameter $\lambda$ :

(i) If $\delta$ is greater than 1 , then SP will choose a totally deregulated market whatever their preferences: $\quad \delta \geq 1 \Rightarrow \hat{\gamma}(\lambda)=0 \quad \forall \lambda$

(ii) If $\delta$ is lower than 1 , then any country with pro-labor orientation lower than $\lambda_{\min }$ (given below) chooses to deregulate totally, whereas SP with a stronger pro-labor inclination decides to regulate according to $\hat{\gamma}(\lambda)>0$. In particular, if $\delta$ is lower than $(1-b)$, any government such that $\lambda \geq \lambda_{\max }$ (given below) chooses to transfer all the rents to workers. Formally,

$$
\begin{aligned}
& \delta \leq 1 \Rightarrow a) \quad \lambda \leq \lambda_{\min }=\delta /(1-b+\delta . b) \quad \Rightarrow \hat{\gamma}(\lambda)=0 \\
& \text { b) } \lambda \geq \lambda_{\max }=\min (\delta /(1-b), 1) \Rightarrow \hat{\gamma}(\lambda)=1 \\
& \text { c) } \lambda_{\min } \leq \lambda \leq \lambda_{\max } \quad \Rightarrow \hat{\gamma}(\lambda)=\frac{1-b}{b} \cdot\left(\frac{1}{\delta}-1\right)-\frac{1}{b} \cdot\left(\frac{1}{\lambda}-1\right)
\end{aligned}
$$

(Proof is directly derived from equation 23 and is given in Appendix 2)

The optimal LM regulation level is positively related to the pro-labor inclination, $\lambda$, and negatively related to the sensitivity of unemployment, $\delta$. The first part of the proposition states that if the unemployment rate is too responsive to regulation $(\delta \geq 1)$, then even the SP most inclined to favor workers will choose to fully deregulate. However, if this is not the case, the redistributive effect

\footnotetext{
${ }^{2}$ Details are available upon requests.
} 
dominates when the social preferences are such that $\lambda \geq \lambda_{\min }$. The SP then decide to regulate all the more, the greater the parameter $\lambda$. To give an intuition of a relevant order of magnitude for $\delta$, consider the maximum "sectoral" unemployment rate achieved when all rents go to workers, $u_{R}^{\max }=u_{R}(\gamma=1) \approx \delta /(\sigma-1)$. Note that the case $\delta \geq 1$ looks fairly extreme for reasonable values of $\sigma$ since it means that $u_{R}^{\max } \geq 1 /(\sigma-1) .^{3}$ Let us now turn to the open economy.

\subsection{Pressure to deregulate the labor market in the open economy}

Based on their respective preferences, the domestic country is assumed to have a regulated LM in autarky in contrast to the foreign country. ${ }^{4}$ Proposition $1 \mathrm{~B}$ states that if the regulation in the domestic country is too favourable to workers all firms move abroad. When trade costs are prohibitive, there always remain some firms in the domestic country (except in the limit case where all rents go to workers). However, when trade costs fall, this bargaining power ceiling diminishes towards zero. With free trade, all firms move to the foreign country, except if the domestic LM is completely deregulated, in which case the FCM equilibrium is reached. In addition, regulating the LM beyond $\gamma_{\max }$ has no additional effect on the economy as the rent sector has disappeared.

However, is it that damaging if all firms move to the foreign country? After all, within this framework, capital owners spend domestically. The answer depends on what the reference point is. If the comparison is with autarky, the answer is: it depends on how costly importing good $R$ is. If the question is between alternative choices of LM policy in the open economy, then total relocation hurts unambiguously. Indeed, let us compute the general price index. Since LM regulation does not affect relative prices, the price index is standard and negatively related to the share of domestic firms:

$$
G^{\text {open }}=\left(\mu . \beta . K^{W^{1 /(1-\sigma)}}\right)^{\alpha} \cdot\left[s_{n}+\phi \cdot\left(1-s_{n}\right)\right]^{\alpha /(1-\sigma)}=G^{\text {autatky }} \cdot\left[\frac{s_{K}}{s_{n}+\phi \cdot\left(1-s_{n}\right)}\right]^{\alpha /(\sigma-1)}
$$

\footnotetext{
${ }^{3}$ The range for the empirical estimates of $\sigma$ is quite large. Based on pricecost margins analyzes, they should not be far from a $[5,8]$ range. However, these analyses almost always assume perfect LM. Because what is measured is in fact the share of the rents kept by firms, taking into account workers' bargaining power leads to a lower range. For instance with $\gamma=0.3$, the range above becomes $[3.8,5.9]$ - for example, $3.8=1+(1-0.3) .(5-1)-$ implying $u_{R}^{\max }$ between $20 \%$ and $36 \%$ for $\delta=1$.

${ }^{4}$ This means that $\delta<1$ and $\lambda *<\lambda_{\min }<\lambda$.
} 
In other words, except if trade is costless, an increase in LM regulation entails an increase in the price index due to firm relocations abroad (because $\partial s_{n} / \partial \gamma<0$ and $\partial G^{o p e n} / \partial s_{n}<0$ ). Very importantly, when comparing the equilibrium corresponding to the fully deregulated $\operatorname{LM}(\gamma=0, \mathrm{FCM})$ with the agglomerated outcome in the foreign country $\left(\gamma \geq \gamma_{\max }\right)$, one notices that wages are identical, equal to 1 , unemployment is zero in both cases and nominal capital returns are equal (see equation $B$ ). However, because the price index is lower in the first case, welfare and the utility of the SP are both greater. What is remarkable about this result is that it holds whatever the social preferences:

$$
\begin{aligned}
\forall \lambda, \quad O B J_{\lambda}\left(\gamma \geq \gamma_{\max }\right) & =\frac{G^{\text {open }}(\gamma=0)}{G^{\text {open }}\left(\gamma \geq \gamma_{\max }\right)} \cdot O B J_{\lambda}(\gamma=0) \\
& =\left[\frac{\phi}{s_{n}(\gamma=0)+\phi \cdot\left(1-s_{n}(\gamma=0)\right)}\right]^{\alpha /(\sigma-1)} . O B J_{\lambda}(\gamma=0) \leq O B J_{\lambda}(\gamma=0)
\end{aligned}
$$

In fact, the full deregulated equilibrium is Pareto superior to the agglomerated one in the foreign country. Equation (26) implies directly that the optimal level of regulation is lower than $\gamma_{\max }=g\left(\phi, \phi^{*}\right)$. As this maximum bargaining power tends to zero when trades becomes costless, the optimal choice is to fully deregulate in that case, whatever the social preferences. This is the main result.

\section{Proposition 3. Optimal level of labor market regulation in the open economy}

(i) Whatever the social preferences parameter, the optimal level of regulation is lower than the level leading to the aggregated equilibrium abroad: $\hat{\gamma}(\lambda) \leq \gamma_{\max } \quad \forall \lambda$

(ii) As trade becomes costless, the optimal choice is to fully deregulate: $\lim _{\phi \rightarrow 1^{-}} \hat{\gamma}(\lambda)=0$

In autarky, the advantage of protection is to increase average wages. With market opening, as local firms are deterred to produce domestically, the redistributive component of LM protection is ineffectual above a threshold. Compared to the deregulated LM situation, it just makes imported goods more expensive. This threshold, in a way the maximum tolerated level, diminishes with trade liberalization. Stated differently, even the slightest protection is non optimal from the point of view of SP when trade becomes very cheap. Indeed, firstly capital mobility puts pressure on LM institutions because of the threat of outflow and secondly, trade liberalization reinforces the attractiveness of being located abroad, so that any positive effect of regulation on SP utility is wiped out when trade is costless. However, as the LM is deregulated, firms are no longer inclined to relocate their activities. The threat 
of relocation drives the changes in LM institutions. In this stylized framework, the effect of liberalization is to be found in the weakening of employment protection, with minimal actual outflows and relocations.

All simulations indicate that the optimal level of LM regulation is a decreasing function of the phi-ness of trade when the domestic country is not too large. However, establishing this relation analytically is probably not possible. Proposition 3 is therefore a weaker result but one strong enough for the main purpose of the paper. If the domestic country is very large / rich then the relationship between the optimal regulation level and the trade costs can be non monotonic and depends on the social preferences parameter as illustrated in Figure 5 with symmetric trade costs. Figure $5 a$ presents the case of the symmetric country where the optimal regulation level decreases in the phi-ness. When SP are utilitarian $(\lambda=0)$ or even when $\lambda$ is sufficiently small then the LM is deregulated whatever the level of trade costs. Figure $5 \mathrm{~b}$ presents the case of alarge / rich country $(s=0.9)$ in which the SP choose optimally to regulate the LM, at least when $\lambda$ is large enough and trade costs reach an intermediate level. Two features are striking. Firstly, in any case the optimal regulation level is lower in the open economy than in autarky. Secondly, the optimal level is flat at zero when $\lambda$ is low. It is hump-shaped when $\lambda$ is intermediate / low and negatively sloped when SP have a high $\lambda$. This pattern is due to two conflicting effects. The first is due to the hump shape of the agglomeration rents which enables the SP to regulate if their social preferences tend to be pro-worker. The second results from the fact that high- $\lambda$ SP opt for a very high degree of LM regulation when the product market is sufficiently closed (low $\phi$ ). This second effect means that in such a country, a gradual opening can only trigger a loosening of regulation from such a high level. The combination of these two effects gives the contrasted patterns depending on the social preferences parameter. For instance, when $\lambda$ is intermediate $(\lambda=0.5$ in Figure $5 b)$, the shape is a combination of that obtained when $\lambda$ is intermediate / low $(\lambda=0.3)$ and when $\lambda$ is high $(\lambda=0.8)$.

\subsection{Impact of market opening on social partners' utility}

Given the pressure to deregulate with market opening, it is natural to compare the autarky and the fully deregulated trade equilibrium. Domestic capital owners unambiguously win in nominal terms with each step of the following sequence (recall Figure $3 c$ ): capital mobility, falling trade costs, full LM 
deregulation. In real terms, this effect is reinforced because trade leads to a fall in prices, at least when $\phi \geq s_{K}$ (see equation 25), and in any case with symmetric countries $\left(s=s_{K}=1 / 2 \Rightarrow\right.$ $\left.s_{n}(\gamma=0)=1 / 2\right)$ : this is one of the sources of the usual gains from trade. This price effect also means that, in the sufficiently open economy, sector- $A$ workers are better off with LM deregulation. Next, autarky unemployed workers find jobs and see their real income increase too. Finally, for sector- $R$ wage earners however, the outcome is not clear-cut. Limiting ourselves to $\phi=\phi^{*}$ leads to:

$$
\begin{aligned}
& \left(\frac{w_{R}}{G}\right)_{\gamma=0}^{\text {open }} \leq\left(\frac{w_{R}}{G}\right)_{\hat{\gamma}^{A}}^{\text {aut }} \Leftrightarrow \frac{1}{G^{\text {open }}(\gamma=0)} \leq \frac{1+\hat{\gamma}^{\text {aut }} /(\sigma-1)}{G^{\text {aut }}} \Leftrightarrow \hat{\gamma}^{\text {aut }} \geq(\sigma-1) \cdot\left[\left(\frac{s_{n}(\gamma=0)+\phi .\left(1-s_{n}(\gamma=0)\right)}{s_{K}}\right)^{\frac{\alpha}{\sigma-1}}-1\right] \\
& \Leftrightarrow \hat{\gamma}^{\text {aut }} \geq(\sigma-1) .\left[\left(\frac{\max (s .(1+\phi), \phi}{s_{K}}\right)^{\alpha /(\sigma-1)}-1\right] \approx \alpha \cdot \log \left(\frac{s}{s_{K}} \cdot(1+\phi)\right) \text { when } \phi \leq \frac{s}{1-s}
\end{aligned}
$$

Real wages improve with market opening and deregulation, only if the initial protection, and therefore the underlying level of the pro-labor orientation, is below a certain level. This implies that when the LM is highly regulated to start with, the combination of liberalization and optimal LM deregulation might generate conflicts of interests and uncover levels of resistance among workers in the rent sector: deregulating is detrimental to them, especially when trade costs are high. ${ }^{5}$ Appendix 3 shows that when trade costs and the pro-labor inclination are high enough then the gains from trade are too low to compensate for the loss of the redistributive tool and SP utility decreases with total LM deregulation.

Does the opening of the economy improve SP utility when the SP choose the optimal LM regulation? Simulations indicate that he general pattern is that opening the economy is beneficial when SP adapts the regulation level optimally. However, when SP have strong pro-labor preferences and therefore highly regulate the LM in autarky, market opening is detrimental to them unless trade costs are low enough.

To sum up, these results highlight how the different liberalizations interact. With capital liberalization, barriers to trade could be harmful, especially if the LM is highly regulated, and therefore, capital mobility renders trade liberalization critical. In turn, falling trade costs reinforces agglomeration and triggers LM deregulation as employment protection becomes ineffective.

\footnotetext{
${ }^{5}$ Unless the country is very labor intensive $\left(s / s_{K}\right.$ large) in which case opening to the world capital market has a strong beneficial price effect as shown by (25).
} 


\subsection{Strategic labor market policy}

We finally contemplate the case where the foreign country might also regulate its $L M$.

\section{Proposition 4. Strategic labor market regulation}

(i) The maximum level of domestic $L M$ regulation is an increasing function of the $L M$ regulation level in the foreign country, a decreasing (increasing) function of the domestic (foreign) phi-ness.

$$
\begin{aligned}
& \gamma_{\max }=1-\frac{\phi \cdot\left(1-\gamma^{*}\right)}{\phi \cdot \phi^{*}+\left(1-\phi \cdot \phi^{*}\right) \cdot\left[s \cdot\left(1-\gamma^{*}\right)+(1-b) \cdot s_{L} \cdot \gamma^{*}\right]} \\
& \Rightarrow \partial \gamma_{\max } / \partial \gamma^{*} \geq 0, \partial \gamma_{\max } / \partial s \geq 0, \partial \gamma_{\max } / \partial \phi \leq 0, \partial \gamma_{\max } / \partial \phi^{*} \geq 0
\end{aligned}
$$

(ii) As importing goods in the domestic country becomes costless, this maximum regulation level is lower than the foreign regulation level: $\quad \forall s \quad \forall \phi^{*}<1 \quad \lim _{\phi \rightarrow 1} \gamma_{\max }<\gamma^{*} \quad, \quad \forall s \lim _{\phi=\phi^{*} \rightarrow 1} \gamma_{\max }=\gamma^{*}$

The straightforward implication is that when trade is fully liberalized, regulation cannot be stricter than in the foreign country and SP strategically choose a level below to attract firms. Therefore, integration with non-cooperation between SP triggers a race to deregulate, whereas cooperation could lead to a different outcome. This suggests that in order to promote their interests, unions should join forces with their foreign counterparts. If not, liberalization induces them to loosen LM regulation sharply.

\section{Conclusion}

This paper is a first attempt at introducing labor market (LM) imperfections in an economic geography setting. The most obvious limitations refer to the specificities of the model integrating wage bargaining in the footloose capital model. Although we have kept away from capital taxation issues per se, as bargaining is directly associated with rent-sharing, this framework presents some similarities with capital taxation used as a redistributive purpose. It is, however, consistent with segmented LMs, which arise because the size of the rents differs across sectors.

However, this framework captures some interesting features, even when the analysis is limited to the case of two countries, differing only in their social preferences, opening to each other. The levels of LM regulation are chosen based on their idiosyncratic social preferences. In autarky, LM protection has the advantage of shifting part of the rents to workers and therefore, of increasing real wages. This 
comes though at the cost of unemployment and lower capital return. Weighing-up these components, the social partners choose the optimal level of protection.

In the context of perfect capital mobility with a country that has a totally deregulated LM (because of its own preferences), the pro-real wage effect of regulation is at best attenuated. Indeed, as firms seeking higher capital return move abroad, total rents diminish and the share kept by workers as well. Within this setting, if the domestic country has a regulated LM initially, market opening will unambiguously benefit capital owners relative to wage earners. In addition, shipping the "delocalised" good has an adverse effect on the purchasing power of domestic consumers. Consequently, the benefits of LM regulation are significantly reduced, or even reversed, by the mobility of capital which leads the government to deregulate.

When trade costs fall the intensity of the agglomeration force increases further. The level of protection beyond which all firms move abroad decreases as trade in goods becomes cheaper. When trade liberalization extends, even the slightest LM protection deters any single firm to produce domestically. The only outcome of LM regulation is then to make the imported goods more expensive compared to the fully deregulated LM equilibrium. As trade tends to become costless, the optimal choice is to totally deregulate the LM. This result is also striking because it holds even if the social partners have a strong pro-worker inclination. The threat of relocation, which becomes more credible when trade costs are low, drives the changes in LM institutions. Consequently, the effect of liberalization might be found primarily in the weakening of employment protection, with minimal actual outflows and relocations.

Obviously, deregulation can generate conflicts of interests. Capital mobility combined with high trade costs makes the wage earners who enjoyed some share of the rents in autarky worse off. If SP have a strong pro-worker preference which is reflected by a high level of regulation in autarky, this situation generates a decrease in SP utility. It is only if the gains from trade, typical of the monopolistic competition, are large enough, i.e. trade costs low enough, that the negative impact of deregulation on real wages is offset. The current model underlines the complexity of analyzing the effects of globalization taken as a single phenomenon, even if focusing on only two aspects, capital and trade liberalization. 
Generally, in terms of economic policy, support for market opening is drawn from models assuming a perfect LM. Taking into account LM regulation, this study highlights how capital and trade liberalization can put pressure on LM institutions. Therefore, liberalization measures should be thought of as tied to the LM deregulation they trigger. This combination might be well accepted by countries with initial low protection. However, countries that attached importance to LM protection may face a difficult situation once engaged in the liberalization process, especially if trade barriers are not so benign. Conversely according to this model, a government, which is prone to liberalize on all fronts, could start with capital, which makes trade protection very costly, then follows with trade openness which eases the burden of high import prices and finally let the SP, potentially undergoing this new environment, opt for LM deregulation and support further trade liberalization in their own interests.

\section{Appendix 1: The Open Economy}

A domestic firm produces $X=x+\tau^{*} \cdot y$, where $x$ and $y$ are sold in the domestic and foreign country respectively. Similarly, for a foreign firm, $X^{*}=x^{*}+\tau \cdot y^{*}$. As in autarky, capital returns are:

$$
\pi=(\mu-1) \cdot(1-\gamma) \cdot \beta \cdot X \quad, \quad \pi^{*}=(\mu-1) \cdot \beta \cdot X^{*}
$$

Therefore, the assumption of perfect capital mobility leads to the equalization of returns, as long as both countries produce good $R$ :

$$
X^{*}=(1-\gamma) . X
$$

The specific effect of potentially different productivity levels between the two countries is reflected in the wages in the foreign country as prices are linked due to trade in good $A: p_{A}=p_{A}^{*}=1 ; w^{*}=A^{*}$; $p^{*}=\mu . \beta=p$. Equation (A2) highlights that because some rents are transferred to workers in the domestic country, domestic firms should be bigger than their foreign competitors in order to cover fixed costs and be able to pay the same return to shareholders. I denoting nominal GNP, worldwide equilibrium in good $R$ is:

$$
\begin{aligned}
& \alpha .\left(I+I^{*}\right)=\mu . \beta .\left(n \cdot X+n^{*} \cdot X^{*}\right) \quad, \quad n+n^{*}=K+K^{*} \\
& I=\pi \cdot K+\vee \cdot L_{R}+L_{A} \quad, \quad I^{*}=\pi * . K^{*}+A^{*} L^{*}
\end{aligned}
$$

Given the equalized returns condition (A2), equation (A3) becomes,

$$
\mu . \beta .\left[n+n^{*} .(1-\gamma)\right] . X=\alpha .\left[\pi .\left(K+K^{*}\right)+v \cdot L_{R}+L_{A}+A^{*} \cdot L^{*}\right]
$$


The production function of good $R$ links sectoral output and employment:

$$
L_{R}=n \cdot X . \beta
$$

Using equation (A1), (A6) and $L_{R}+L_{A}=L .(1-u)$, equation (A5) becomes:

$$
\begin{gathered}
\mu . \beta \cdot\left[n+n^{*} \cdot(1-\gamma)\right] . X=\alpha \cdot\left[(\mu-1) \cdot(1-\gamma) \cdot\left(K+K^{*}\right) \cdot \beta \cdot X+(\nu-1) \cdot n \cdot \beta \cdot X+L \cdot(1-u)+A^{*} \cdot L^{*}\right] \Leftrightarrow \\
X=\frac{\alpha}{\beta} \cdot \frac{L \cdot(1-u)+A^{*} L^{*}}{\mu \cdot\left[n+n^{*} \cdot(1-\gamma)\right]-\alpha \cdot(\mu-1) \cdot\left[n+(1-\gamma) \cdot n^{*}\right]}=\frac{\alpha}{\beta} \cdot \frac{L \cdot(1-u)+A^{*} L^{*}}{K+K^{*}} \cdot \frac{\sigma-1}{(\sigma-\alpha) \cdot\left(1-\gamma+\gamma \cdot s_{n}\right)}
\end{gathered}
$$

From (A 1), the equilibrium capital return is then easily obtained:

$$
\pi=\alpha \cdot \frac{L \cdot(1-u)+A^{*} L^{*}}{K+K^{*}} \cdot \frac{1-\gamma}{(\sigma-\alpha) \cdot\left(1-\gamma+\gamma \cdot s_{n}\right)}=\frac{b}{1-b} \cdot \frac{L \cdot(1-u)+A^{*} L^{*}}{K+K^{*}} \cdot \frac{1-\gamma}{1-\gamma+\gamma \cdot s_{n}}
$$

Classically with iceberg trade costs, $p_{y}=\tau^{*} \cdot p_{x}=\tau^{*} \cdot p=\tau^{*} \cdot \mu . \beta$ and $p_{y}^{*}=\tau \cdot p_{x}^{*}=\tau \cdot p^{*}=\tau \cdot \mu . \beta$, and therefore, Dixit-Stiglitz preferences imply: $y^{*}=x \tau^{-\sigma}$ and $y=x^{*} \tau^{*^{-\sigma}}$. The equilibrium for good $R$ in the domestic and foreign country is respectively:

$$
\begin{aligned}
& \alpha \cdot I=n \cdot p \cdot x+n^{*} \cdot p_{y}^{*} \cdot y^{*}=\mu \cdot \beta \cdot x \cdot\left(n+\phi \cdot n^{*}\right) \Rightarrow x=\frac{1}{\mu \cdot \beta} \cdot \frac{\alpha \cdot I}{n+\phi \cdot n^{*}} \\
& x^{*}=\frac{1}{\mu \cdot \beta} \cdot \frac{\alpha \cdot I^{*}}{\phi^{*} n+\phi} \Rightarrow y=\frac{\tau^{*}-\sigma}{\mu \cdot \beta} \cdot \frac{\alpha \cdot I^{*}}{\phi^{*} \cdot n+n^{*}}
\end{aligned}
$$

Combining equations (A9a) and (A9b) to get $X=x+\tau * . y$ and reciprocally for $X^{*}=x^{*}+\tau \cdot y^{*}$ gives:

$$
\begin{aligned}
& \frac{I}{n+\phi . n^{*}}+\frac{\phi^{*} \cdot I^{*}}{\phi^{*} n+n^{*}}=\frac{\mu . \beta}{\alpha} \cdot X \\
& \frac{\phi . I}{n+\phi . n^{*}}+\frac{I^{*}}{\phi^{*} n+n^{*}}=\frac{\mu \cdot \beta}{\alpha} \cdot X^{*}=\frac{\mu \cdot \beta}{\alpha} \cdot(1-\gamma) \cdot X
\end{aligned}
$$

It is already clear that, when $\phi$ tends to 1 , the system (A10a)-(A10b) implies that the bargaining power cannot be strictly positive even if $\phi^{*}=1$. Eliminating $I$ from the system (A10a)- (A10b) leads to:

$$
\phi^{*} n+n^{*}=\frac{\alpha}{\mu . \beta} \cdot \frac{\left(1-\phi \cdot \phi^{*}\right) \cdot I^{*}}{X \cdot[1-\gamma-\phi]}=\frac{\alpha}{\mu \cdot \beta} \cdot \frac{\left(1-\phi \cdot \phi^{*}\right) \cdot\left(\pi \cdot K^{*}+A^{*} L^{*}\right)}{X \cdot(1-\gamma-\phi)}
$$

Substituting successively the expressions of the capital return and of a domestic firm's output given by (A1) and (A7) leads to the first relationship linking the location of firms to the unemployment rate:

$$
\begin{aligned}
& \phi^{*} n+n^{*}=\frac{\alpha}{\mu \cdot \beta} \cdot \frac{\left(1-\phi \cdot \phi^{*}\right) \cdot\left[(\mu-1) \cdot(1-\gamma) \cdot \beta \cdot X \cdot K^{*}+A^{*} L^{*}\right]}{X \cdot(1-\gamma-\phi)} \\
& \Rightarrow 1-\left(1-\phi^{*}\right) s_{n}=\frac{1-\phi \cdot \phi^{*}}{1-\gamma-\phi} \cdot\left[b \cdot(1-\gamma) \cdot s_{K}^{*}+(1-b) \frac{s_{L}^{*} \cdot\left(1-\gamma+\gamma \cdot s_{n}\right)}{1-u \cdot s_{L}}\right]
\end{aligned}
$$


It is convenient to denote $s=b \cdot s_{K}+(1-b) \cdot s_{L}$. The weighting of factor shares in $s$ highlights that when the share of spending in good $R$ and/or the degree of market power is high, i.e. $b$ is large, then the spatial distribution of capital owners matters the most. Conversely, when $b$ is small, labor distribution across countries is crucial. After some manipulations, equation (A11) leads to (14) in the main text:

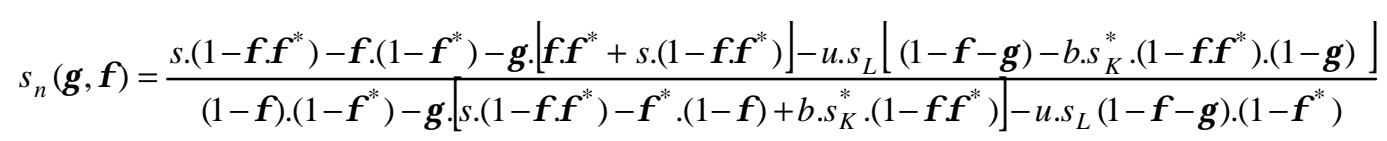

In order to reach the second relationship, i.e. equation (15), we need to calculate the sectoral employment. This is achieved easily by combining (A6) and (A7):

$$
\begin{aligned}
& L_{R}=\frac{b}{1-b} \cdot(\sigma-1) \cdot\left[L \cdot(1-u)+A^{*} L^{*}\right] \frac{s_{n}}{1-\gamma+\gamma \cdot s_{n}} \Rightarrow u=\left(1-\frac{L_{A}}{L}\right) u_{R}=\left(1-\frac{L \cdot(1-u)-L_{R}}{L}\right) f(v) \\
& \Rightarrow \frac{u}{1 / s_{L}-u}=\frac{b}{1-b} \cdot(\sigma-1) \cdot \frac{f(v)}{1-f(v)} \cdot \frac{s_{n}}{1-\gamma+\gamma \cdot s_{n}}=\frac{u^{A}(\gamma)}{1-u^{A}(\gamma)} \cdot \frac{s_{n}}{1-\gamma+\gamma \cdot s_{n}}
\end{aligned}
$$

\section{Agglomeration in the foreign country (Proof of Proposition $1 A$ and $1 B$ (i))}

When the activity is agglomerated in the foreign country, $s_{n}=0$ and given (A13) the unemployment rate is zero due to specialization in sector $A$. The sustain-point is the parameter where the numerator of (A12) is equal to zero. Substituting the expression of $s_{n}$ given by (A12) into (A13) leads to the full expression of the unemployment rate in the open economy:

$$
\phi \leq \phi_{S}^{F} \Leftrightarrow u(\gamma, \phi)=\frac{u^{A}(\gamma)}{s_{L}} \cdot \frac{s \cdot\left(1-\phi \cdot \phi^{*}\right)-\phi \cdot\left(1-\phi^{*}\right)-\gamma \cdot\left[\phi \cdot \phi^{*}+s \cdot\left(1-\phi \cdot \phi^{*}\right)\right]}{(1-\phi) \cdot\left(1-\phi^{*}\right)-\gamma \cdot\left[(1-\phi) \cdot\left(1-\phi^{*}\right)+\left(\phi-\phi^{*}\right)\right]-\varsigma}
$$

where $\varsigma=\left\lfloor\gamma \cdot \phi^{*}+b \cdot s_{K}^{*} \cdot\left(1-\phi \phi^{*}\right) \cdot(1-\gamma) \mid\left[\gamma+(1-\gamma) \cdot u^{A}\right]+(1-\phi-\gamma) \phi^{*} \cdot(1-\gamma) \cdot u^{A}\right.$ is a second order term:

$$
\phi \leq \phi_{S}^{F} \Leftrightarrow u(\gamma, \phi) \approx \frac{u^{A}(\gamma)}{s_{L}} \cdot \frac{g\left(\phi, \phi^{*}\right)-\gamma}{\frac{(1-\phi) \cdot\left(1-\phi^{*}\right)}{\phi . \phi^{*}+s \cdot\left(1-\phi \phi^{*}\right)} \cdot(1-\gamma)}=\frac{u^{A}(\gamma)}{s_{L}} \cdot \frac{\psi-\gamma}{\chi \cdot(1-\gamma)}
$$

where $\psi \equiv g\left(\phi, \phi^{*}\right) \equiv \frac{s \cdot\left(1-\phi \cdot \phi^{*}\right)-\phi \cdot\left(1-\phi^{*}\right)}{\phi \cdot \phi^{*}+s \cdot\left(1-\phi \cdot \phi^{*}\right)}$ and $\chi \equiv \frac{(1-\phi) \cdot\left(1-\phi^{*}\right)}{\phi \cdot \phi^{*}+s \cdot\left(1-\phi \cdot \phi^{*}\right)}$

Furthermore this approximation is exact in the two following cases: the unemployment rate is zero either when the LM is totally deregulated $\left(\gamma=0 \Rightarrow u^{A}=0\right)$ or when the agglomerated equilibrium is reached $\left(\phi \geq \phi_{S}^{F} \Leftrightarrow \gamma \geq \psi \Rightarrow s_{n}=0\right.$ and $\left.u=0\right)$. Combining (A13) and (A14) leads to: 


$$
\begin{aligned}
\phi \leq \phi_{S}^{F} \Leftrightarrow \gamma \leq \psi \Rightarrow s_{n} & =\frac{(1-\gamma) \cdot u \cdot\left(1-u^{A}\right)}{u^{A} \cdot\left(1 / s_{L}-u\right)-\gamma \cdot u \cdot\left(1-u^{A}\right)} \approx \frac{(1-\gamma) \cdot u}{u^{A} / s_{L}-\gamma \cdot u} \\
& \approx \frac{\psi-\gamma}{\chi-\gamma \cdot \frac{\psi-\gamma}{1-\gamma}} \approx \frac{\psi-\gamma}{\chi-\gamma \cdot \psi} \approx \frac{\psi-\gamma}{\chi}=\frac{s \cdot\left(1-\phi \cdot \phi^{*}\right)-\phi \cdot\left(1-\phi^{*}\right)-\gamma \cdot\left[\phi \cdot \phi^{*}+s .\left(1-\phi \cdot \phi^{*}\right)\right]}{(1-\phi) \cdot\left(1-\phi^{*}\right)}
\end{aligned}
$$

It is therefore obvious that $\partial s_{n} / \partial \gamma<0$. Simple differentiation shows that:

$$
\operatorname{sign}\left(\partial s_{n} / \partial \phi\right)=-(1-s) .\left(1-\phi^{*}\right)<0 \quad \text { and } \operatorname{sign}\left(\partial s_{n} / \partial \phi^{*}\right)=s-\frac{\gamma}{1-\gamma} \cdot \frac{\phi}{1-\phi}
$$

Moreover, $\gamma \leq \psi \Leftrightarrow \frac{\gamma}{1-\gamma}<\frac{s .(1-\phi)-\phi .(1-s) \cdot\left(1-\phi^{*}\right)}{\phi}<\frac{s .(1-\phi)}{\phi} \Rightarrow \frac{\partial s_{n}}{\partial \phi^{*}}>0$

In order to complete the proof, we differentiate (A14): $\frac{\partial u}{\partial \gamma}=\frac{1}{s_{L} \cdot \chi \cdot(1-\gamma)} .\left[(\psi-\gamma) \frac{d u^{A}}{d \gamma}-\frac{1-\psi}{1-\gamma} \cdot u^{A}\right]$

When the bargaining power is small, $u^{A}$ is small, the first term between brackets dominates and the unemployment rate is an increasing function of $\gamma$. Conversely, when the bargaining power is close to the sustain-point $(\gamma \rightarrow \psi)$, the second term dominates and the unemployment rate decreases with $\gamma$.

\section{Agglomeration in the domestic country (Proof of Proposition 1B (ii))}

When the activity is agglomerated in the domestic country, $s_{n}=1$ and (A13) entails $u=u^{A} / s_{L}$ :

$\left.\left.(\mathrm{A} 12) \Rightarrow s_{n} \geq 1 \Leftrightarrow s \cdot\left(1-\phi \cdot \phi^{*}\right)-\left(1-\phi^{*}\right) \geq \gamma \cdot \mid \phi^{*}-\left(1-\phi \cdot \phi^{*}\right) b \cdot s_{K}^{*}\right\rfloor+u^{A} \cdot \mid \phi^{*} \cdot(1-\phi-\gamma)-b \cdot s_{K}^{*} \cdot\left(1-\phi \cdot \phi^{*}\right) \cdot(1-\gamma)\right\rfloor$

It can be shown that this necessarily implies that $\phi^{*}>\left(1-\phi \phi^{*}\right) b \cdot s_{K}^{*}$ and therefore:

$\gamma_{\min } \approx \max \left[0, \frac{s \cdot\left(1-\phi \cdot \phi^{*}\right)-\left(1-\phi^{*}\right)}{\phi^{*}}\right]$ and with symmetric trade costs: $\gamma_{\min } \approx \frac{1-\phi^{2}}{\phi} \max \left[0, s-\frac{1}{1+\phi}\right]$.

To complete the proof, note that $\forall \phi \frac{1}{1+\phi}>\frac{1}{2}$ and $s>\frac{1}{1+\phi} \Leftrightarrow \phi>\frac{s}{1-s}$. It is straightforward to show that $\gamma_{\min }$ is hump-shaped in $\phi$ and reaches a maximum when $\phi=\left(\frac{s}{1-s}\right)^{1 / 2}$

\section{Stategic labor market policy (Proposition 4)}

Introducing LM regulation in the foreign country simply modifies (A2) into $\left(1-\gamma^{*}\right) X^{*}=(1-\gamma) . X$ and repeating the steps from (A3-A13) leads ultimately to $\gamma_{\max }=1-\frac{\phi \cdot\left(1-\gamma^{*}\right)}{\phi . \phi^{*}+\left(1-\phi . \phi^{*}\right) \cdot\left[s \cdot\left(1-\gamma^{*}\right)+(1-b) \cdot s_{L} \cdot \gamma^{*}\right]}$. 


\section{Appendix 2: Proof of Proposition 2}

Using equation (9) leads to the expression of nominal GDP, $I$, and SP utility:

$$
\begin{aligned}
& I=p \cdot X_{R}+X_{A}=\mu \cdot \beta \cdot X_{R}+X_{A}=\mu \cdot L_{R}+L_{A}=\left(\frac{\sigma \cdot \alpha}{\sigma-\alpha}+\frac{\sigma \cdot(1-\alpha)}{\sigma-\alpha}\right) \cdot L \cdot(1-u)=\frac{L \cdot(1-u)}{1-b} \\
& O B J_{\lambda}=\frac{G D P-\lambda \cdot \pi \cdot K}{G}=\frac{1-\lambda \cdot b \cdot(1-\gamma)}{G .(1-b)} \cdot L \cdot(1-u)
\end{aligned}
$$

hence (22). Differentiating this expression with respect to the bargaining power leads to:

$$
\frac{d \log O B J_{\lambda}}{d \gamma} \geq 0 \Leftrightarrow \frac{-d u / d \gamma}{1-u}+\frac{\lambda . b}{1-\lambda \cdot b \cdot(1-\gamma)} \geq 0 \Leftrightarrow \gamma \leq 1-\frac{1}{b \cdot \lambda}+\frac{1-u}{d u / d \gamma}
$$

$\delta$ being a constant representing the sensitivity of the unemployment rate to the regulation level, we choose the following functional form: $u_{R}=f(v)=\frac{1-e^{-b /(1-b) \cdot \delta \cdot \gamma}}{1-\frac{1-b \cdot \sigma}{1-b} \cdot e^{-b /(1-b) . \delta \cdot \gamma}} \approx \frac{1}{\sigma-1} \delta \cdot \gamma=\delta .(v-1)$.Indeed this entails from (11): $u=1-e^{-b /(1-b) . \delta . \gamma}$ and therefore, $d u / d \gamma=b /(1-b) . \delta .(1-u)$. It follows that:

$$
\frac{d \log O B J_{\lambda}}{d \gamma} \geq 0 \quad \Leftrightarrow \quad \gamma \leq 1-\frac{1}{b . \lambda}+\frac{1-b}{b . \delta} \equiv \varphi(\lambda, \delta) \quad, \quad \varphi(1,1)=0 \quad \varphi_{\lambda} \equiv \frac{\partial \varphi}{\partial \lambda}>0 \quad \varphi_{\delta} \equiv \frac{\partial \varphi}{\partial \delta}<0
$$

Therefore, whatever the level of parameter $\lambda(\leq 1)$, if $\delta$ is greater than $1, \varphi(\lambda, \delta) \leq \varphi(1, \delta)<\varphi(1,1)=0$. This means that, in this case, SP utility is strictly decreasing with the bargaining power and therefore, the SP choose to fully deregulate, which proves (i) of Proposition 2 . When $\delta$ is lower than 1 , it is easy to verify that $0 \leq \frac{\delta}{1-b+b . \delta} \leq 1$ and $\varphi\left(\frac{\delta}{1-b+b . \delta}, \delta\right)=0$. Therefore, if $\lambda \leq \lambda_{\min } \equiv \delta /(1-b+b . \delta)$ then $\varphi(\lambda, \delta)<0$ and $\hat{\gamma}(\lambda)=0$, hence (ii) a). Moreover, as $\varphi(\delta /(1-b), \delta)=1$, if social preferences are such that $\lambda \geq \lambda_{\text {max }} \equiv \delta /(1-b)$ then all rents are transferred to workers and $\hat{\gamma}(\lambda)=1$. In the intermediate case where $\lambda_{\min } \leq \lambda \leq \lambda_{\max }, \hat{\gamma}(\lambda)=\frac{1-b}{b} \cdot\left(\frac{1}{\delta}-1\right)-\frac{1}{b} \cdot\left(\frac{1}{\lambda}-1\right)$

\section{Appendix 3: Comparison between autarky and fully deregulated open economy}

Based on (A15), SP utility in autarky is $O B J_{\lambda}^{A}\left(\hat{\gamma}^{A}\right)=\left[G^{A} \cdot(1-b)\right]^{-1} \cdot\left(1-u^{A}\right) \cdot\left[1-\lambda \cdot b \cdot\left(1-\hat{\gamma}^{A}\right)\right] \cdot L$ and:

$$
O B J_{\lambda}^{T}(\gamma=0)=\left[G^{A} \cdot(1-b)\right]^{-1} \cdot\left(\frac{\max (s .(1+\phi), \phi}{s_{K}}\right)^{\frac{\alpha}{\sigma-1}} \cdot[1-\lambda . b .] L \quad\left[=\max \left(\frac{s \cdot(1+\phi)}{\phi}, 1\right)^{\frac{\alpha}{\sigma-1}} O B J_{\lambda}^{T}(\gamma \geq \psi), \forall \lambda\right]
$$


(which proves Proposition 3 more explicitly). It follows that:

$$
O B J_{\lambda}^{T}(\gamma=0)<O B J_{\lambda}^{A}\left(\gamma=\hat{\gamma}^{A}\right) \Leftrightarrow\left(\frac{\max (s .(1+\phi), \phi}{s_{K}}\right)^{\frac{\alpha}{\sigma-1}} .(1-\lambda \cdot b)<\left(1-u^{A}\right) .\left(1-\lambda \cdot b .\left(1-\hat{\gamma}^{A}\right)\right)
$$

Using the specific form $f$ detailed in Appendix 2 and following Proposition 2, if $\delta \leq 1-b$ and $\lambda \geq \lambda_{\max }=\delta /(1-b)$ then the optimal bargaining power equals 1 in autarky. Therefore, based on the autarky unemployment rate given by $(24 b)$ :

$\lambda \geq \lambda_{\max } \Rightarrow\left(O B J_{\lambda}^{T}(\gamma=0)<O B J_{\lambda}^{A}\left(\gamma=\hat{\gamma}^{A}\right) \Leftrightarrow\left(\frac{\max (s \cdot(1+\phi), \phi}{s_{K}}\right)^{\frac{\alpha}{\sigma-1}} .(1-\lambda . b)<1-u^{A}=\exp (-b . \delta /(1-b))\right.$

Moreover, $1>\exp (-b . \delta /(1-b)) \geq \exp (-b)>1-b \Rightarrow \exists \tilde{\lambda} \in] 0,1[$ such that $\exp (-b . \delta /(1-b))=1-\tilde{\lambda} . b$ :

$\lambda \geq \lambda_{\max } \Rightarrow\left(O B J_{\lambda}^{T}(\gamma=0)<O B J_{\lambda}^{A}\left(\gamma=\hat{\gamma}^{A}\right) \Leftrightarrow\left(\frac{\max (s .(1+\phi), \phi}{s_{K}}\right)^{\frac{\alpha}{\sigma-1}}<(1-\tilde{\lambda} . b) /(1-\lambda . b)\right)$

If $\mathrm{SP}$ are such that $\lambda>\max \left(\lambda_{\max }, \tilde{\lambda}\right)$ then the last term on the RHS is greater than 1 and, for low enough phi-ness, total deregulation is detrimental in terms of SP utility compared to autarky (the same remark as in footnote 7 applies).

\section{References}

Baker, D., A. Glyn, D.R. Howell, J. Schmitt, 2005. Labor Market Institutions and Unemployment: A Critical Assessment of the Cross-Country Evidence, in Fighting Unemployment: The Limits of Free Market Orthodoxy, D.R. Howell, ed., Oxford University Press.

Baldwin, R., R. Forslid, P. Martin, G. Ottaviano, F. Robert-Nicoud, 2003. Economic Geography and Public Policy. Princeton University Press.

Bertrand, M., 2004. From the Invisible Handshake to the Invisible Hand? How Import Competition Changes the Employment Relationship. Jounral of Labor Economics, 22(4), 723-766.

Blanchard, O., 2005. European unemployment: the evolution of facts and ideas. NBER WP 11750.

Blanchard, O., F. Giavazzi, 2003. Macroeconomic Effects of Regulation and Deregulation in Goods and Labor Markets. Quarterly Journal of Economics CXVIII (3), 879-908. 
Borjas, G.J., V.A. Ramey, 1995. Foreign Competition, Market Power and Wage Inequality. Quarterly Journal of Economics, November, 1075-1110.

Boulhol, H., S. Dobbelaere, S. Maioli, 2006. Imports as Product and Labor Market Discipline. IZA Discussion Paper 2178.

Brandt, N., J.-M. Burniaux, R. Duval, 2005. Assessing the OECD jobs strategy : past development and reforms. OECD Working Paper 429.

Davis, D.R., 1998. Does European Unemployment Prop Up American Wages? National Labor Markets and Global Trade. American Economic Review, 88(3), 478-494.

Dreher, A., N. Gaston, 2005. Has Globalisation Really Had No Effect on Unions? KOF WP 110, ETH.

Dumont, M., G. Rayp and P. Willemé, 2006, Does internationalization affect union bargaining power? An empirical study for five EU countries, Oxford Economic Papers, 58, 77-102.

Ebell, M., C. Haefke, 2006. Product Market Regulation and Endogenous Union Formation. IZA Discussion Paper 2222.

Freeman, R., 2006. Searching for the EU Social Dialogue Model. NBER WP 12306.

Gaston, N., D. Nelson, 2004. Structural Change and the Labor-market Effects of Globalization. Review of International Economics, 12(5), 769-792.

IMF, 2004. Fostering Structural Reforms in Industrial Countries. World Economic Outlook.

Kramarz, F., 2003. Wages and International Trade. CEPR Discussion Paper 3936.

Martin, P., C.A. Rogers, 1995. Industrial location and public infrastructure. Journal of International Economics, 39 (3/4), 335-352.

McDonald, I.M., R.M. Solow, 1985. Wages and Employment in a Segmented Labor Market. Quarterly Journal of Economics 100 (4), 1115-1141.

Nicoletti, G., S. Scarpetta, 2005. Product market reforms and employment in OECD countries. OECD Working Paper 472.

OECD, 2004. Employment Outlook.

Rodrik, D., 1997. Has Globalization gone too far? Institute for International Economics.

Saint-Paul, G., 2004. Why are European Countries Diverging in their Unemployment Experience? Journal of Economic Perspectives 18(4), 49-68.

Spector, D., 2004. Competition and the capital-labor conflict. European Economic Review 48, 25-38. 
Figure 1

Changes in product market regulation over 1993-1998

and intensity of labour market reforms over 2000-2004

Labour market reform intensity, per cent

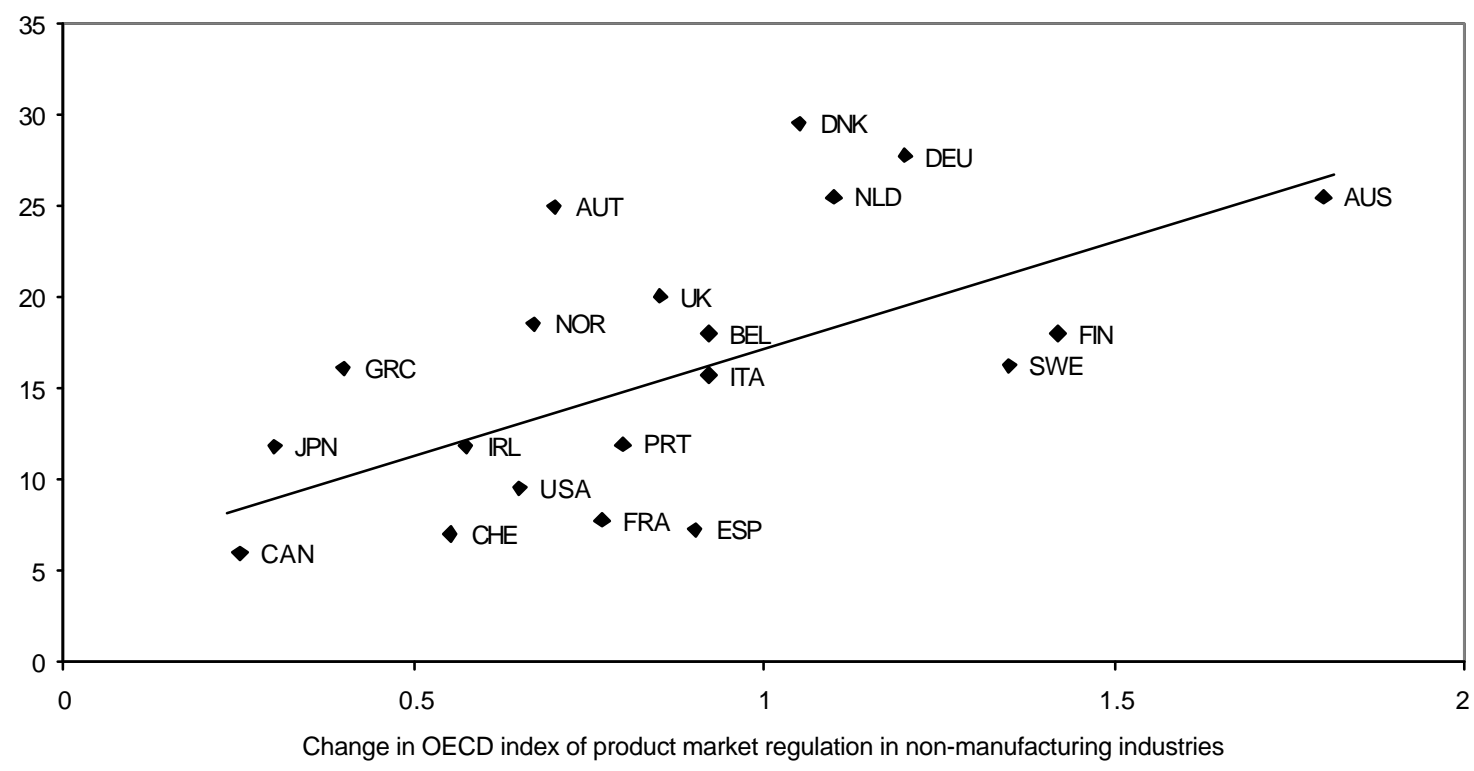

Correlation coefficient: 0.51

t-statistics

$2.58^{* *}$

Source: Figure 34 in Brandt et al. (2005) 
Figure 2: Scissors Diagram

\section{Share of the sector $R$ domestic firms as a function of the relative size $s$ of the domestic country}
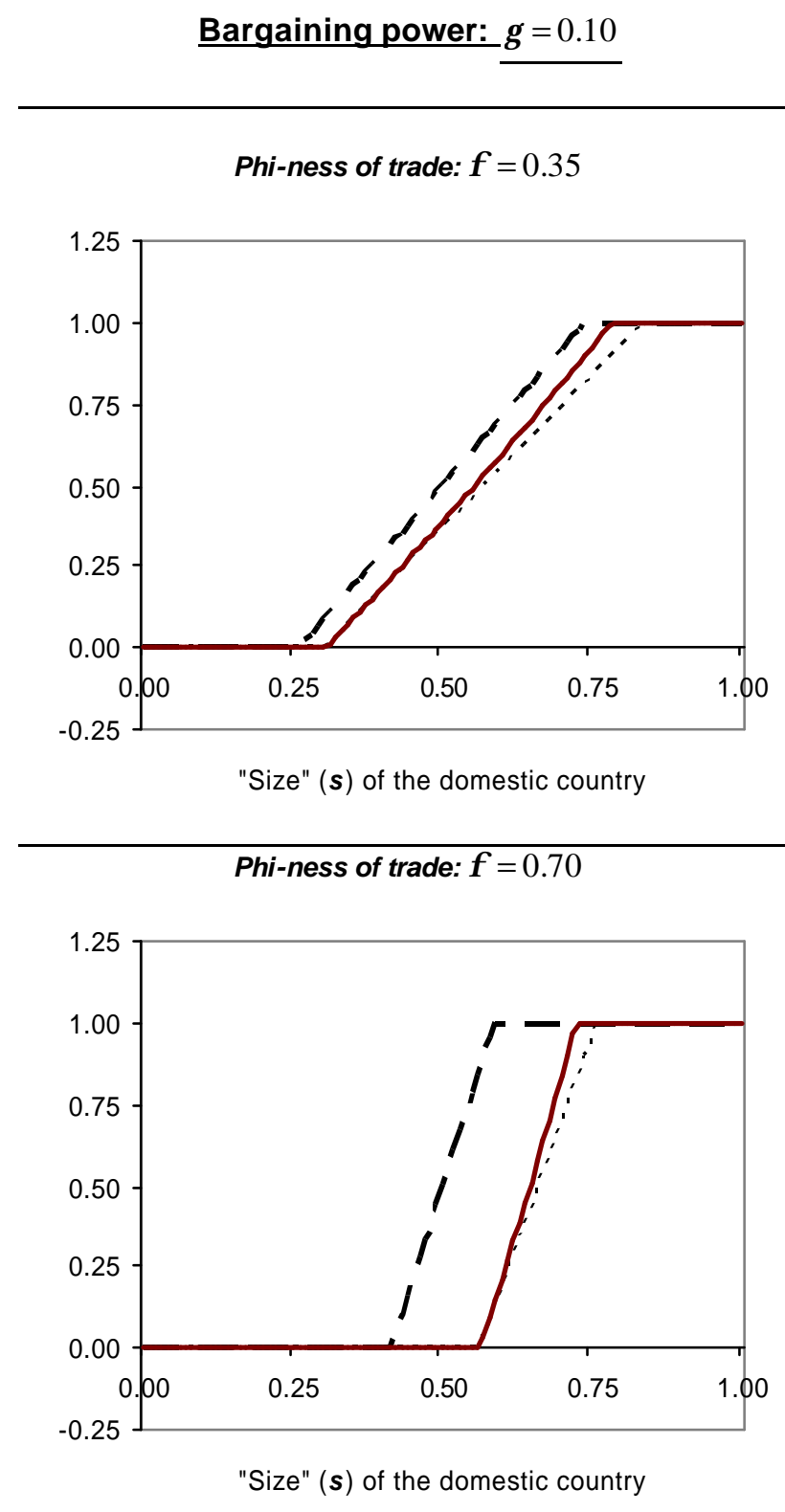

Bargaining power: $\gamma=0.30$

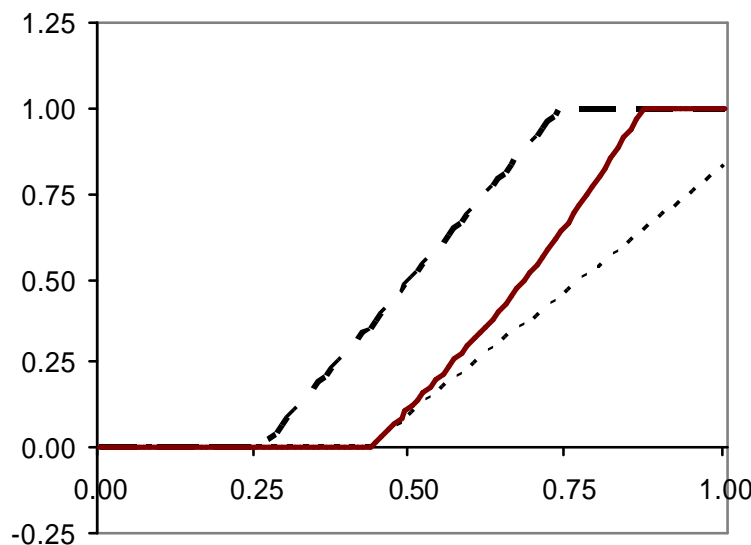

"Size" (s) of the domestic country

Phi-ness of trade: $\phi=0.70$

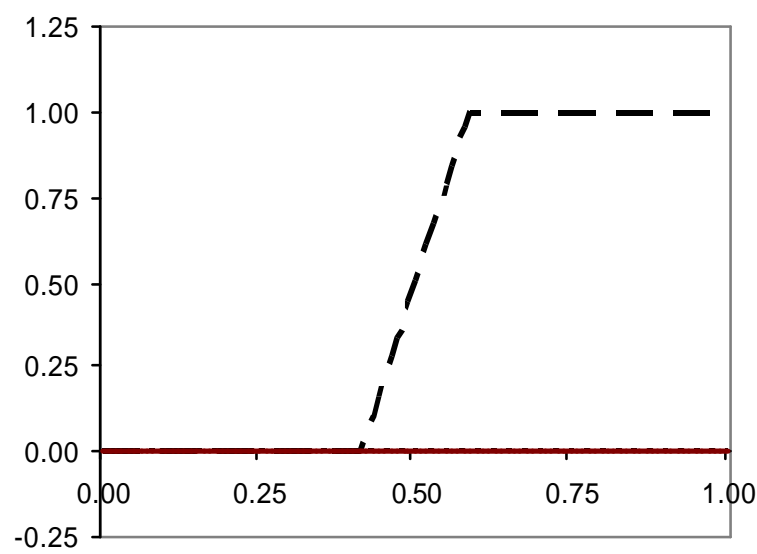

"Size" (s) of the domestic country Standard FCM $(\gamma=0)$ $s_{n} \quad-\cdots$ approximated $s_{n}$

\section{Note.}

The simulation for $s_{n}$ is based on the specific function $f(v)=\delta .(v-1)$ (see section 4). However, the impact of the parameter $\delta$ is insignificant such that the expression given by equation (16) $s_{n} \approx(\psi-\gamma) /(\chi-\gamma . \psi)$ cannot be distinguished from the true value. The curve labelled "approximated $s_{n}$ " comes from one further approximation: $s_{n} \approx(\psi-\gamma) / \chi \quad$ and proves to be close to the true value. With $s_{n} \approx(\psi-\gamma) /(\chi-\gamma . \psi) \quad$, equation (17) becomes : $s_{n}=\frac{\psi-\gamma}{\chi-\gamma . \psi} \Leftrightarrow s_{n}=\frac{1}{2}+\frac{1}{1-\gamma \cdot \frac{s .(1+\phi)-\phi}{1-\phi}}\left[\frac{1+\phi}{1-\phi} \cdot\left(s-\frac{1}{2}\right)-\gamma \cdot\left(\frac{\phi^{2}+s \cdot\left(1-\phi^{2}\right)+\phi}{2 .(1-\phi)^{2}}\right)\right]$ which demonstrates that the slope is steeper than the one resulting from the approximation. 
Figure 3

Symmetric Countries in terms of Size and Trade Costs: $s=1 / 2, \tau=\tau^{*}$

Fig. 3a: Unemployment Rate in the Domestic Country

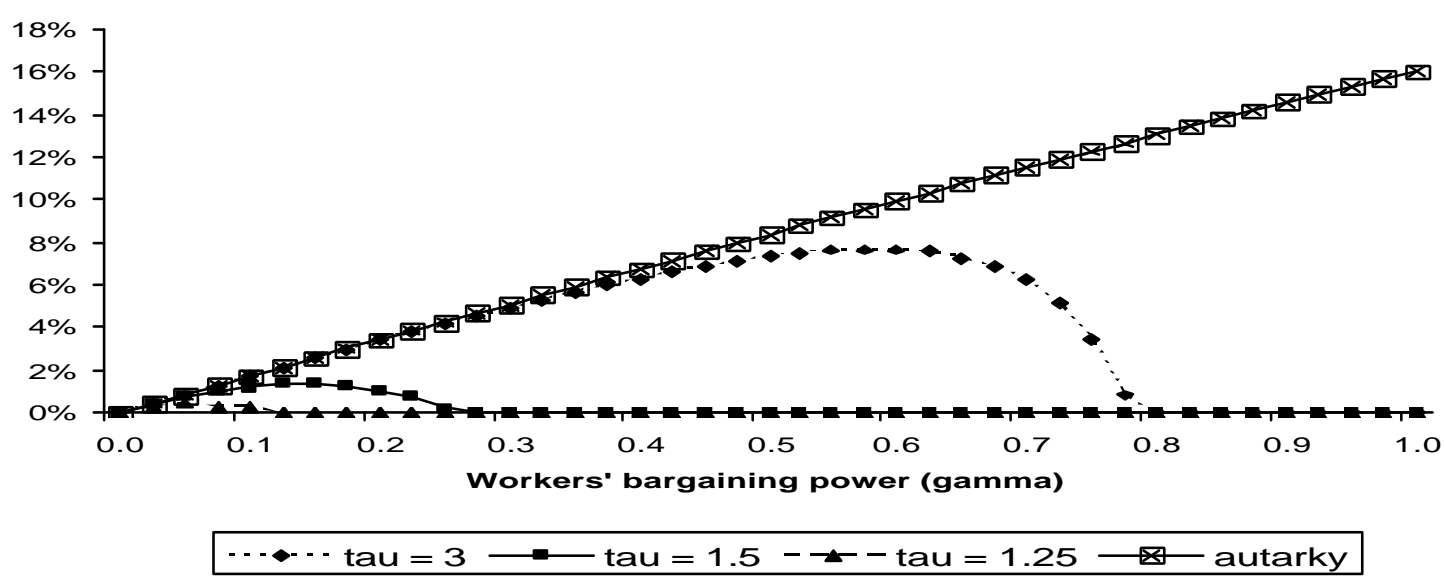

Fig. 3b: Share of Domestic Firms in Sector $R$

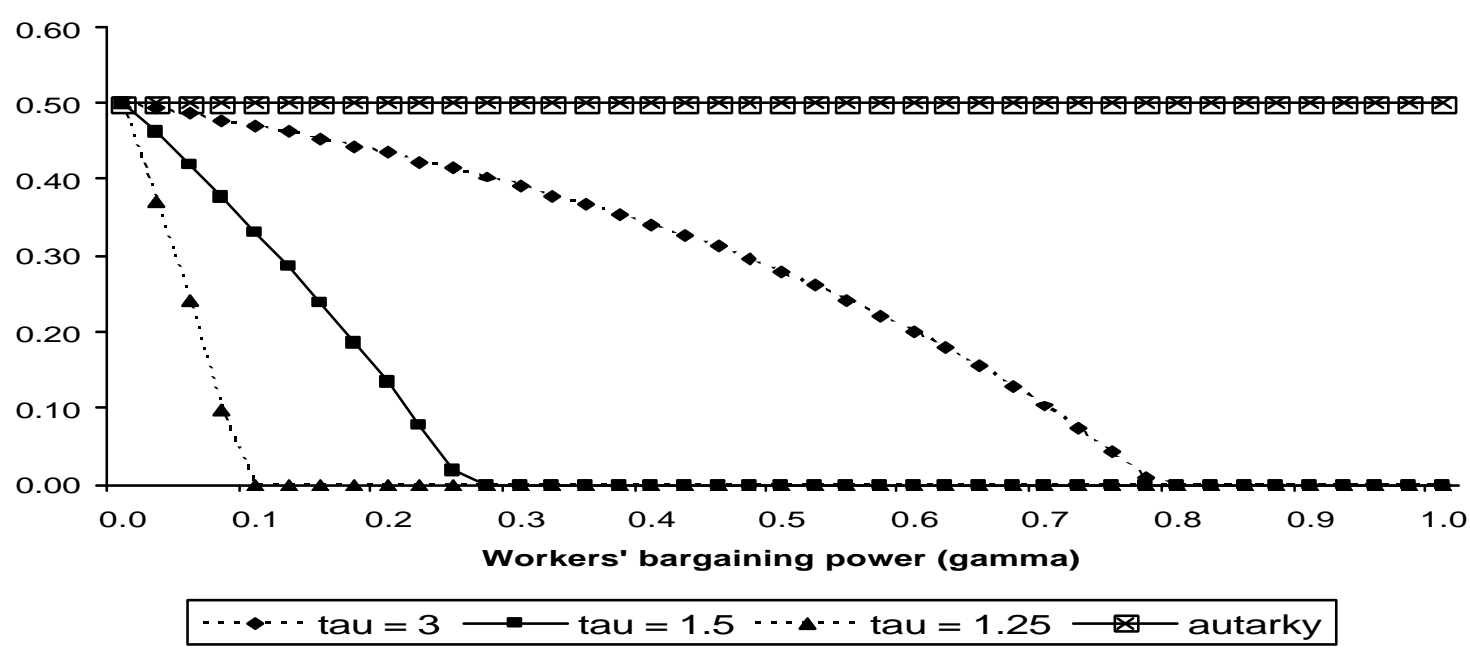

Fig. 3c: Capital Return (foreign autarky return =1)

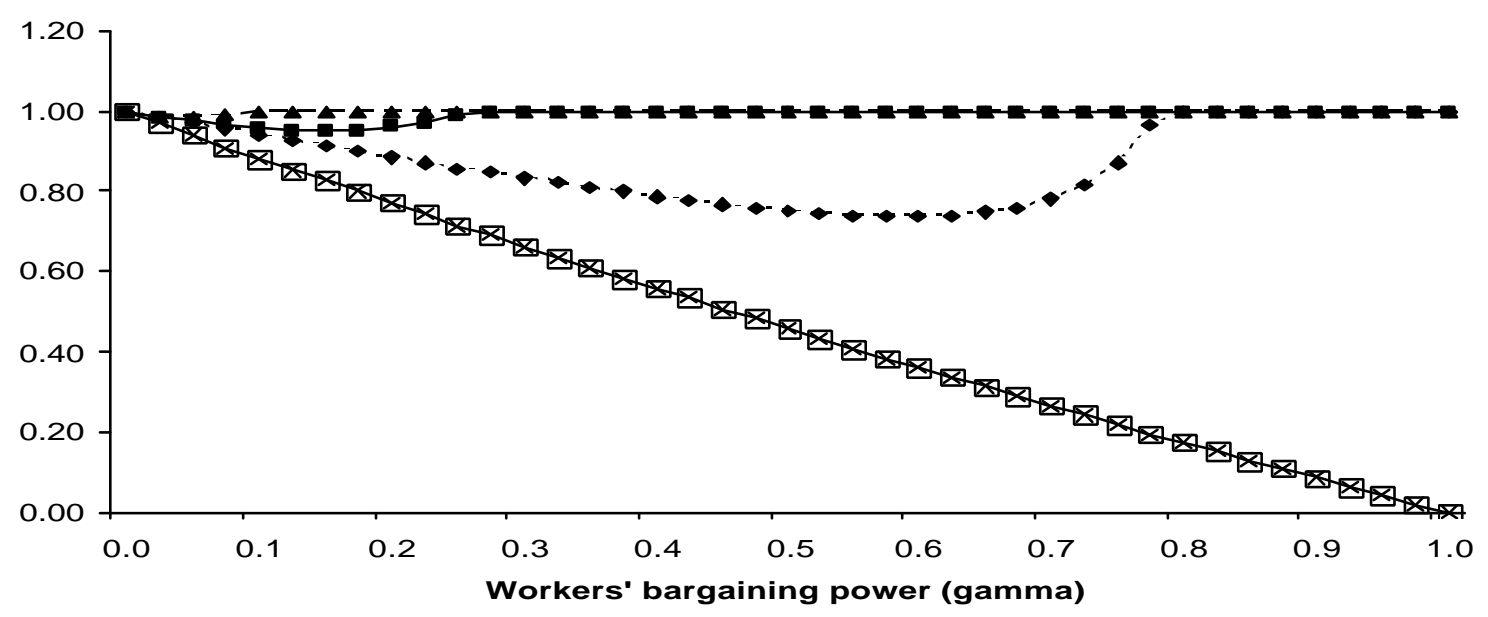

$\cdots \bullet$ tau $=3 \longrightarrow$ tau $=1.5---$ tau $=1.25 \longrightarrow$ autarky 
Figure 4

\section{Agglomeration and Sustain Points}

Bargaining power threshold levels for agglomeration with asymmetric trade costs $\left(s=0.5 ; \phi^{*}=0.3\right.$ )

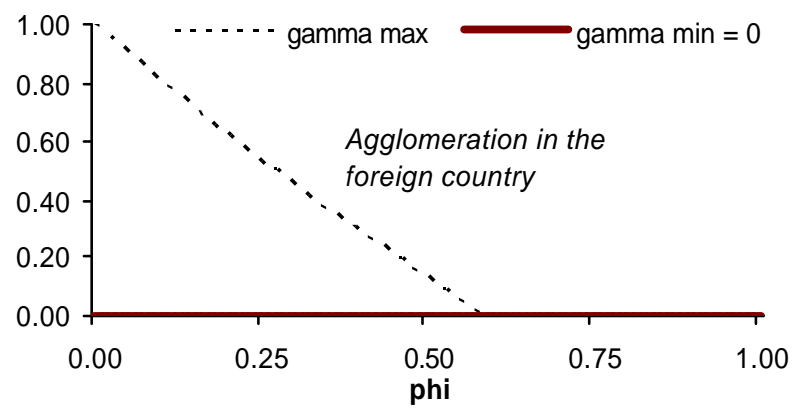

Bargaining power threshold levels for agglomeration with asymmetric trade costs $\left(s=0.5 ; \phi^{*}=0.6\right)$

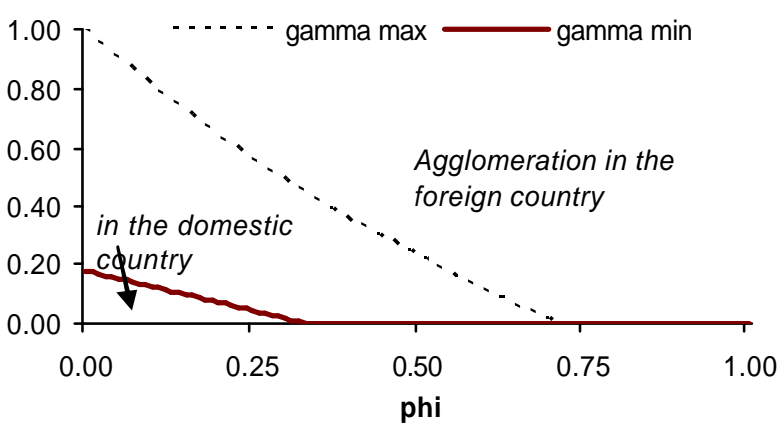

Sustain point $\left(\gamma_{\min }\right)$ for the agglomeration in thedomestic country with asymmetric trade costs $\left(\phi^{*}=0.6\right)$

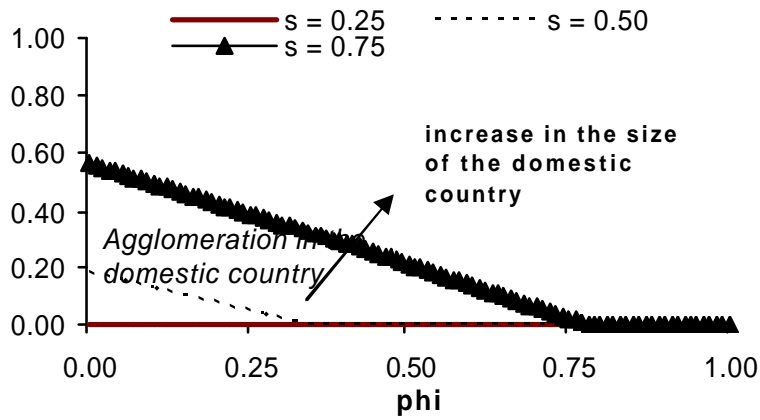

Sustain points $\left(\gamma_{\min }, \gamma_{\max }\right)$ with symmetric trade costs $\left(\phi=\phi^{*}\right)$ when the domestic country is "large" $(s=0.9)$

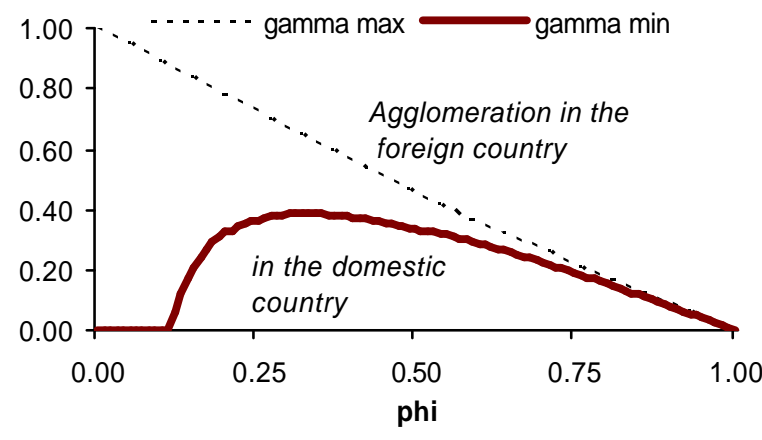


Figure 5a

Optimal Level of Labor Market Regulation as a Function of Trade Costs

Symmetric countries and trade costs $\left(s=0.5, \phi=\phi^{*}\right)$

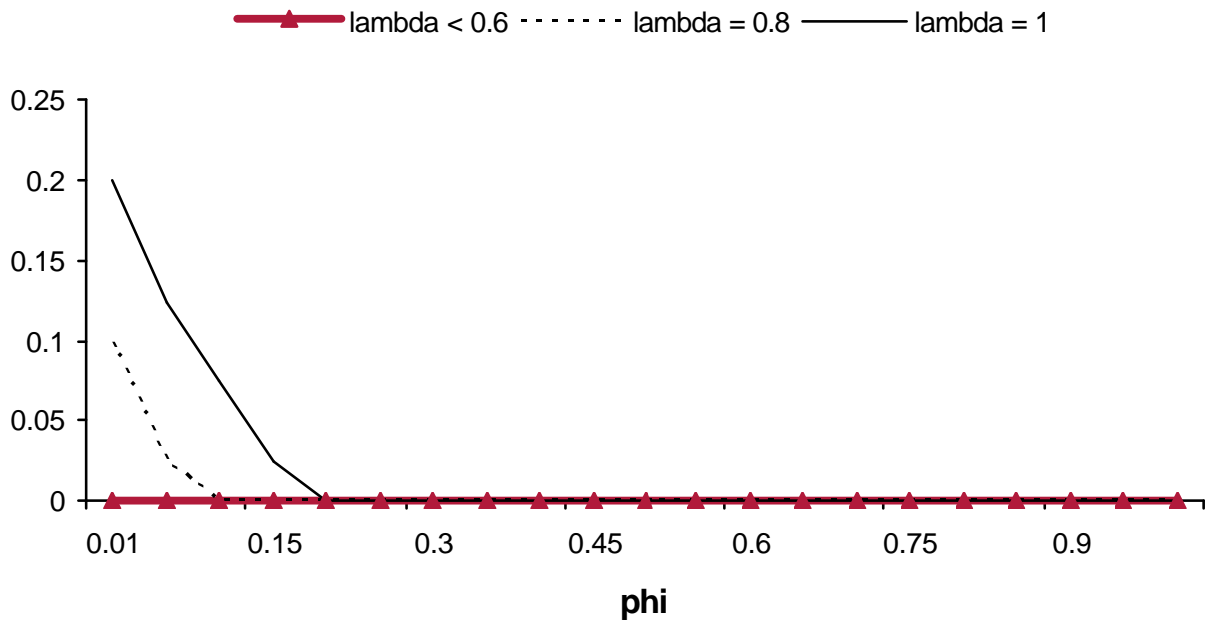

Figure 5b

Optimal Level of Labor Market Regulation as a Function of Trade Costs

Large / Rich country $\left(s=0.9, \phi=\phi^{*}\right)$

- - lambda $=0.3 \longrightarrow$ lambda $=0.5 \cdots \cdots \cdot$ lambda $=0.8 \longrightarrow$ lambda $=1$

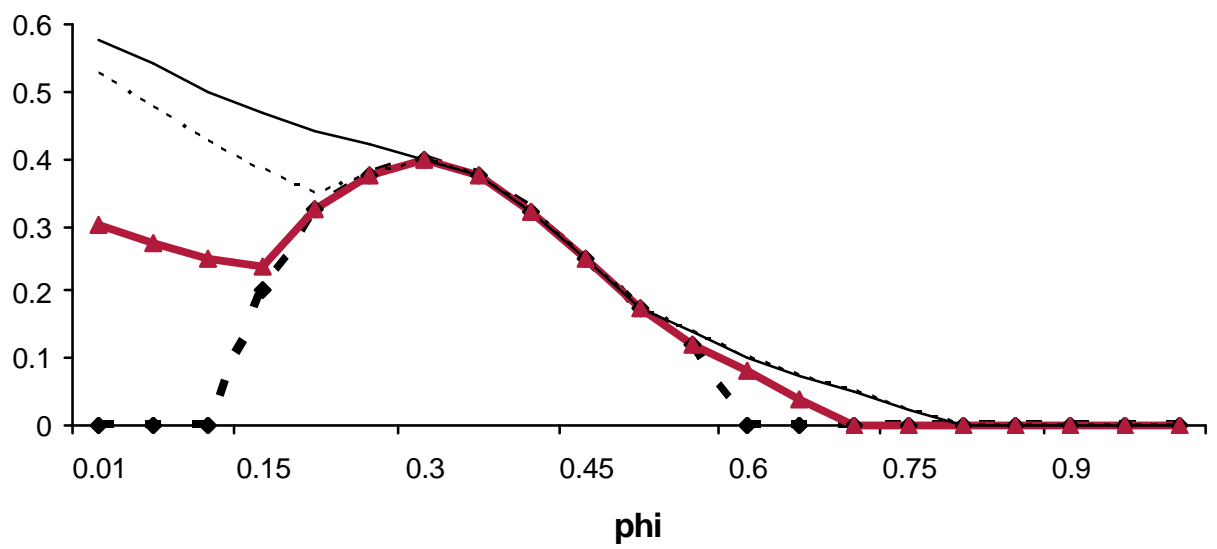

Autarky LM regulation levels are $\hat{\gamma}^{A}(\lambda<0.25)=0, \hat{\gamma}^{A}(\lambda=0.30)=0.32, \hat{\gamma}^{A}(\lambda>0.40)=1$ 